\title{
CLAVES Y DATOS NUEVOS DE LAS ESPECIES IBÉRICAS DEL GÉNERO STELIS PANZER, 1806 (HYMENOPTERA, APOIDEA, MEGACHILIDAE, ANTHIDIINI) ${ }^{1}$
}

\author{
C. Ornosa*, F. Torres** \& F. J. Ortiz-Sánchez***
}

\begin{abstract}
RESUMEN
El trabajo actual, dentro de la revisión que se está realizando de la familia Megachilidae en la fauna ibérica, incluye las claves de identificación para las especies del género Stelis Panzer, 1806. Las claves se acompañan de numerosas ilustraciones para su reconocimiento inmediato. El estudio incluye también registros nuevos y citas anteriores corregidas o actualizadas.

Palabras clave: Abejas, parásitas, Hymenoptera, Apoidea, Megachilidae, Anthidiini, Stelis, claves, Península Ibérica.
\end{abstract}

\section{ABSTRACT \\ Keys and new data about Iberian species of Stelis Panzer, 1806 (Hymenoptera, Apoidea, Megachilidae, Anthidiini)}

This paper includes keys to the Iberian species of the genus Stelis (Hymenoptera, Apoidea, Megachilidae, Anthidiini) as part of the ongoing general revision of the Iberian taxa of Megachilidae. The accompanying illustrations should make instant identification possible. Information about new, mistaken or doubtful records is also included.

Key words: Parasitic, bees, Hymenoptera, Apoidea, Megachilidae, Anthidiini, Stelis, keys, Iberian Peninsula.

\section{Introducción}

Las abejas del género Stelis son especies cleptoparásitas de diferentes especies de megaquílidos, que se distribuyen por el reino holártico y en la región oriental. En la fauna ibérica aparecen 10 especies: 3 de ellas contaban hasta ahora con sólo una o dos citas en España (Ornosa et al., 2008).

El estudio actual presenta las claves de identificación para las especies ibéricas de este género. Las claves son originales, así como las imágenes, dibujos $\mathrm{y}$ fotografías, aunque se han manejado las realizadas

* Departamento de Zoología y Antropología Física. Facultad de Biología. Universidad Complutense. c/ José Antonio Nováis, 2. E-28040 Madrid, España. E-mail: paddy@bio.ucm.es

** Departamento de Biología Animal, Ecología, Parasitología y Edafología. Universidad de Salamanca. Campus Miguel de Unamuno s/n. E-37071 Salamanca, España. E-mail: torres@usal.es

*** Grupo de Investigación "Transferencia de I+D en el Área de Recursos Naturales". Universidad de Almería. E-04120 La Cañada de San Urbano (Almería), España. E-mail: fjortiz@ual.es Subvencionado por el Proyecto CGL2007-60877 


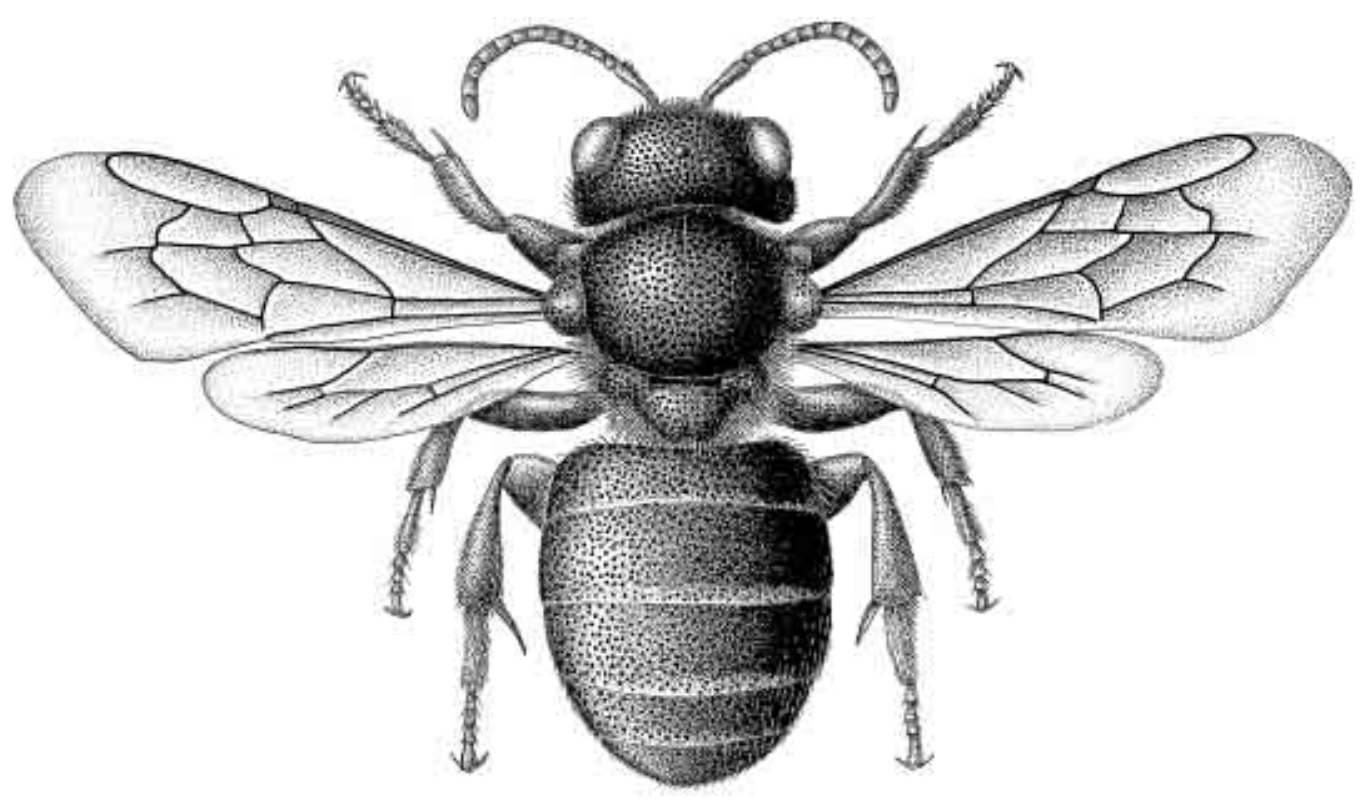

Fig. 1._ Vista general del macho de Stelis punctulatissima.

Fig. 1.- Male of Stelis punctulatissima in general view.

previamente por los autores que han tratado el tema (Radoszkowski, 1862; Friese, 1895; Dusmet, 1921; Popov, 1932, 1935; Noskiewicz, 1926, 1961; Warncke, 1992). Stelis es un género muy uniforme, de especies morfológicamente similares, reunidas desde hace tiempo en subgéneros (Friese, 1895; Popov, 1932, 1935; Noskiewicz, 1961; Pasteels, 1969; Michener \& Griswold, 1994; Michener, 2007), que no siempre han sido considerados de ese modo (Popov, 1938; Warncke, 1992). En este artículo, a pesar de que en las publicaciones más recientes se siguen manteniendo estos subgéneros con cierto grado de incertidumbre (Michener, 2007; Ornosa et al. 2008), no se reconocen, porque estudios moleculares preliminares, que el equipo investigador de los autores está realizando, arrojan resultados poco definitivos por el momento.

\section{Material y métodos}

Para realizar este estudio se han revisado las colecciones de las siguientes instituciones: Museo Nacional de Ciencias Naturales de Madrid (MNCN), Instituto Valenciano de Investigaciones Agrarias de Valencia (IVIA), Estación Experimental de Zonas Áridas de Almería (EEZA), Departamento de
Biología Animal, Ecología, Parasitología y Edafología de la Universidad de Salamanca (USAL) y Departamento de Zoología y Antropología Física de la Universidad Complutense de Madrid (UCM), además de especímenes del Museo Nacional de Historia Natural de París, del Museo Zoológico de Berlín y la colección particular de uno de los autores (F. J. Ortiz-Sánchez) (FJOS). Del material examinado, sólo se refieren en el texto los ejemplares que representan nuevos registros o citas corregidas o enmendadas.

Debe señalarse también que, aunque en las claves hubiera sido preferible utilizar exclusivamente dibujos, se ha recurrido en gran medida a fotografías, no siempre tan explicativas, porque, en su mayoría, los individuos en que se basan son muy antiguos, algunos cuentan con más de un siglo y son poco susceptibles de ser manipulados sin riesgo. Hay que tener en cuenta que se trata de un grupo de especies muy poco abundante, muchas de ellas raras y difíciles de conseguir fuera del material de colecciones.

\section{CARACTERES DiAgNósticos Y TERMinOLOGÍA EMPLEADA}

Las especies de este género (Fig. 1) presentan un aspecto externo semejante al de las especies de 

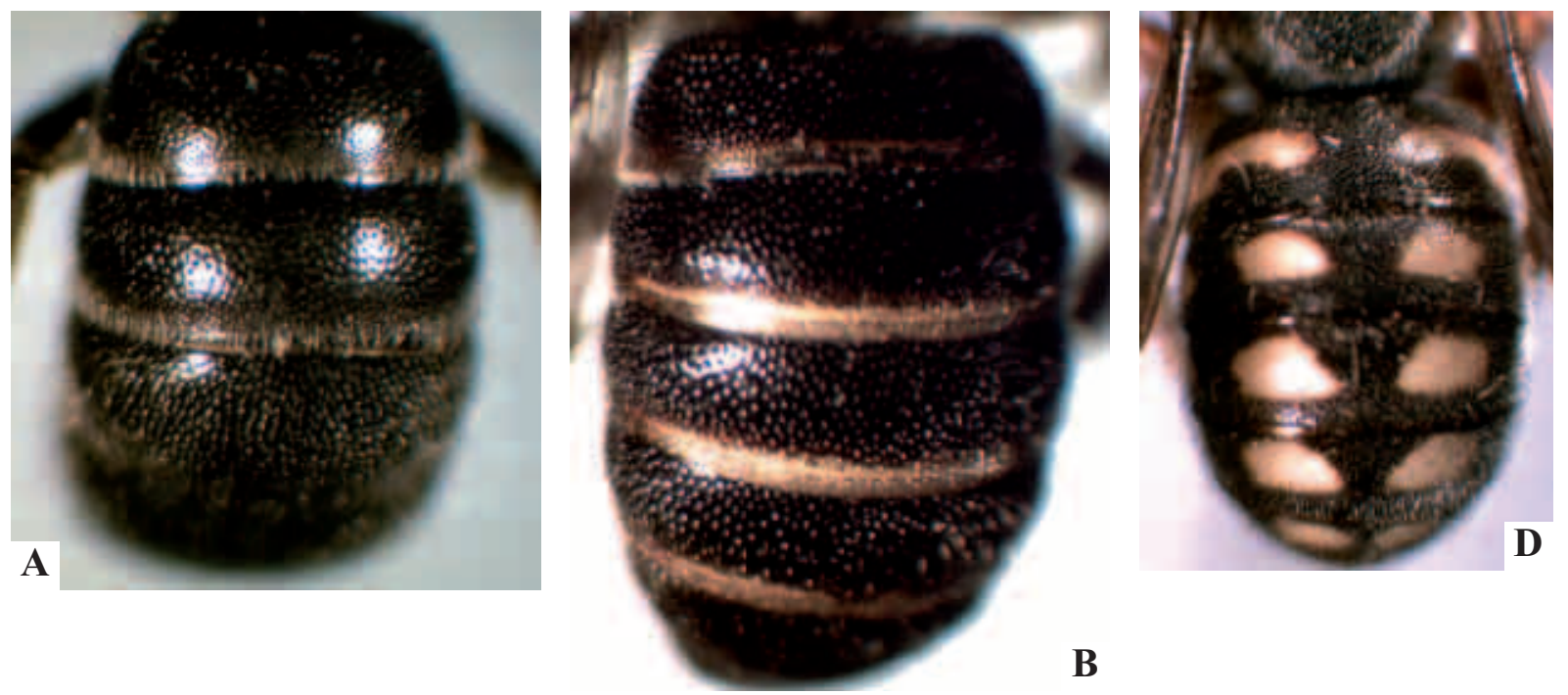

B

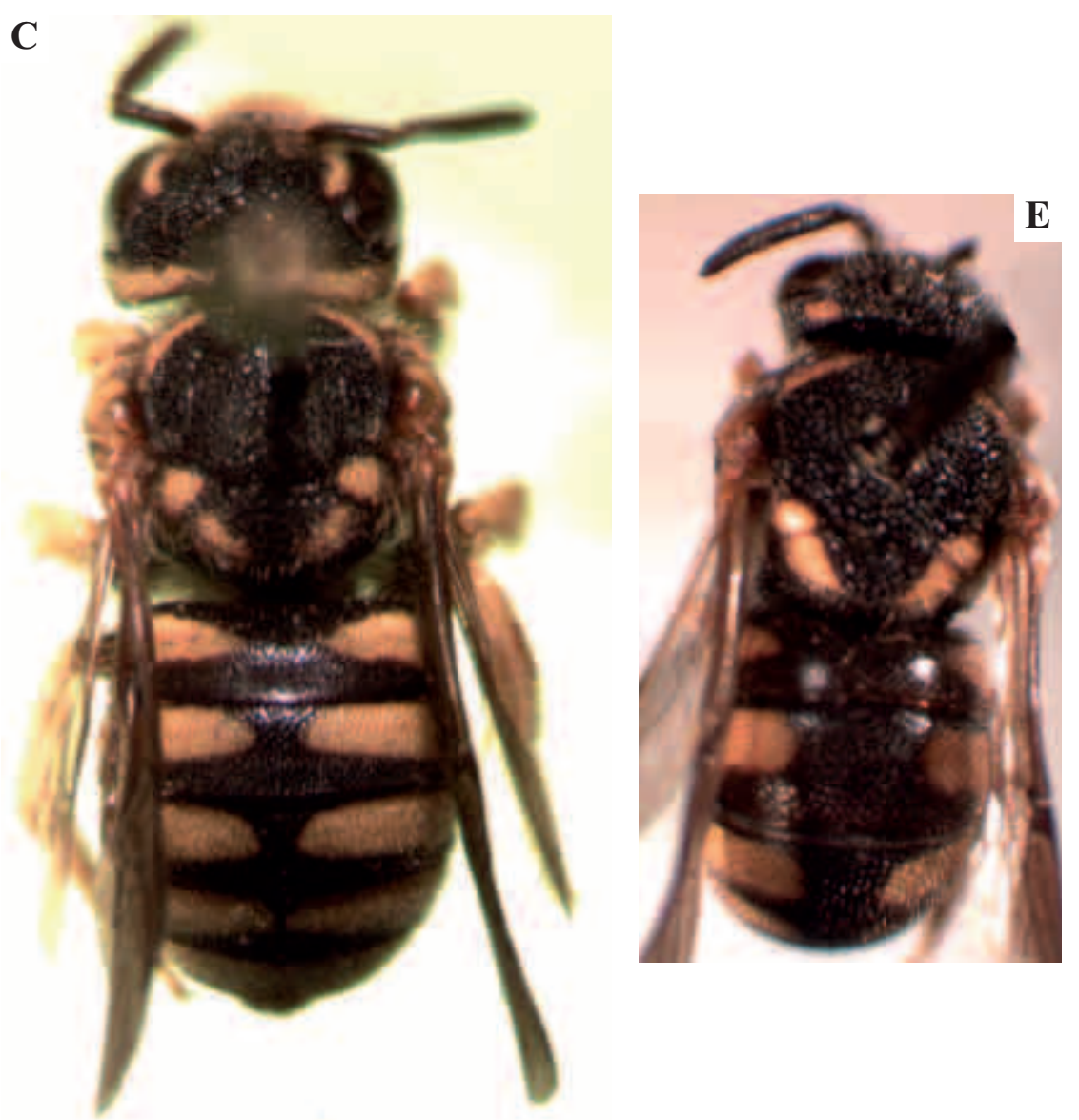

Fig. 2.- Vista general del gáster de las hembras de Stelis: S. breviuscula (A), S. punctulatissima (B), S. annulata (C), S. nasuta (D) y $S$. signata (E).

Fig. 2.- Stelis female gastrum in general view: S. breviuscula (A), S. punctulatissima (B), S. annulata (C), S. nasuta (D) and S. signata (E). 
A

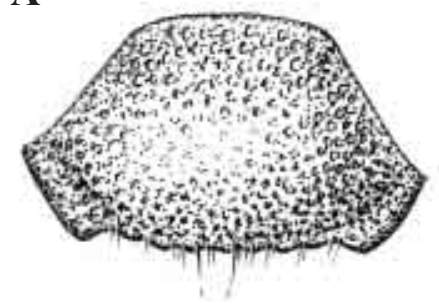

B

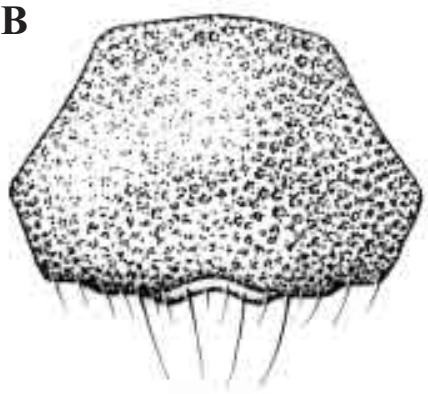

C

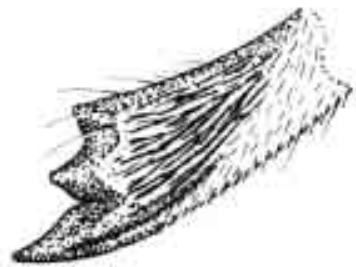

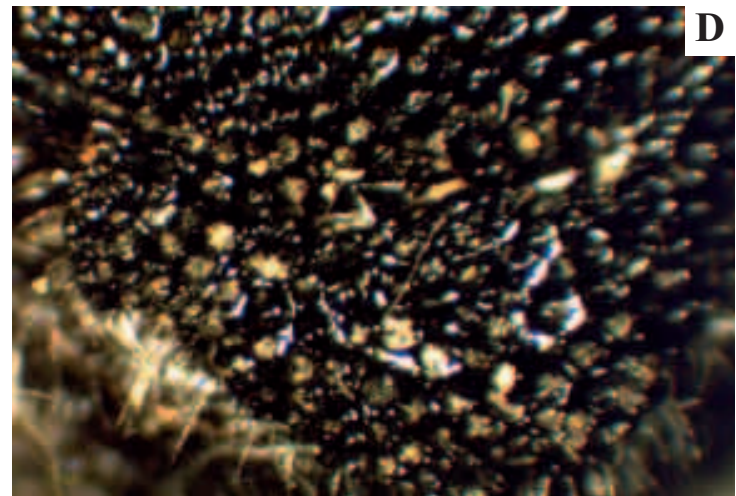

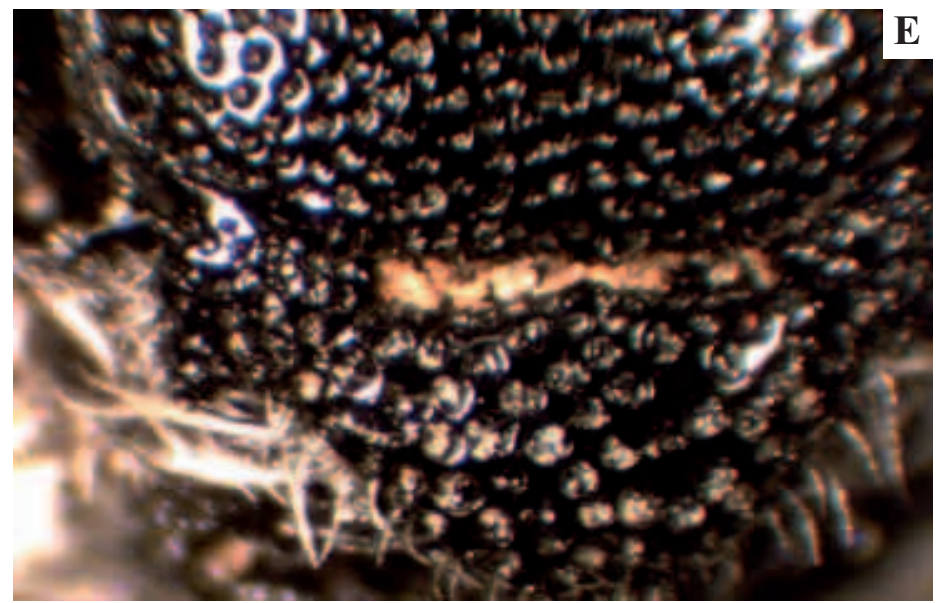

Fig. 3.- Esquema en vista frontal del clípeo de la hembra de Stelis phaeoptera (A) y del clípeo (B) y de la mandíbula (C) de la hembra de S. punctulatissima; vista dorsal de la escultura del escutelo de la hembra de S. punctulatissima (D) y de S. simillima.

Fig. 3.- Female clypeus of Stelis phaeoptera in front view (A) and female clypeus (B) and mandible (C) of S. punctulatissima; scutellum sculpture of $S$. punctulatissima female (D) and $S$. simillima female (E) in dorsal view.

otros Anthidiini. Se caracterizan porque los machos son de tamaño igual o menor que las hembras, por tener en la cabeza el labro muy alargado (Figs. 4A, 4B y 4C), cuya longitud es notablemente mayor que su anchura, y mandíbulas casi siempre tridentadas (Fig. 3C). En el vértex, se considera como distancia preoccipital la que separa los ocelos laterales y el borde del occipucio y como unidad se utiliza el diámetro $(\varnothing)$ de uno de tales ocelos laterales. En las antenas, se diferencian los componentes habituales: el escapo basal, el pedicelo y un flagelo con 10 (en las hembras) u 11 (en los machos) flagelómeros o artejos antenales. Como norma general, el primer artejo flagelar se toma como el tercero de la antena y los flagelómeros se representan abreviadamente por medio de una A, seguida del subíndice del ordinal correspondiente.
Convencionalmente, se denomina "tórax" lo que en los Apocrita es realmente el conjunto del tórax con el primer segmento del abdomen, el propodeo, que se le ha fusionado. Como resultado, el abdomen aparente, en abejas y otros himenópteros, se denomina gáster o metasoma. En el tórax, el escutelo (Fig. 3D) puede ser inerme o presentar dientes laterales más o menos marcados, pero nunca muy desarrollados, a modo de largas espinas. En el par de alas anterior, la celda marginal es grande, adelgazada en el extremo, y las dos submarginales son casi iguales (Fig. 1). Además, el $2^{\circ}$ nervio transverso-discoidal (o recurrente $2^{\circ}$ ) está situado más hacia el ápice del ala que el $2^{\circ}$ transverso-submarginal, no en línea con éste o más adentro (Fig. 1), como en otros Anthidiini. En las patas, existen arolios entre las uñas. El propodeo es muy estrecho, 

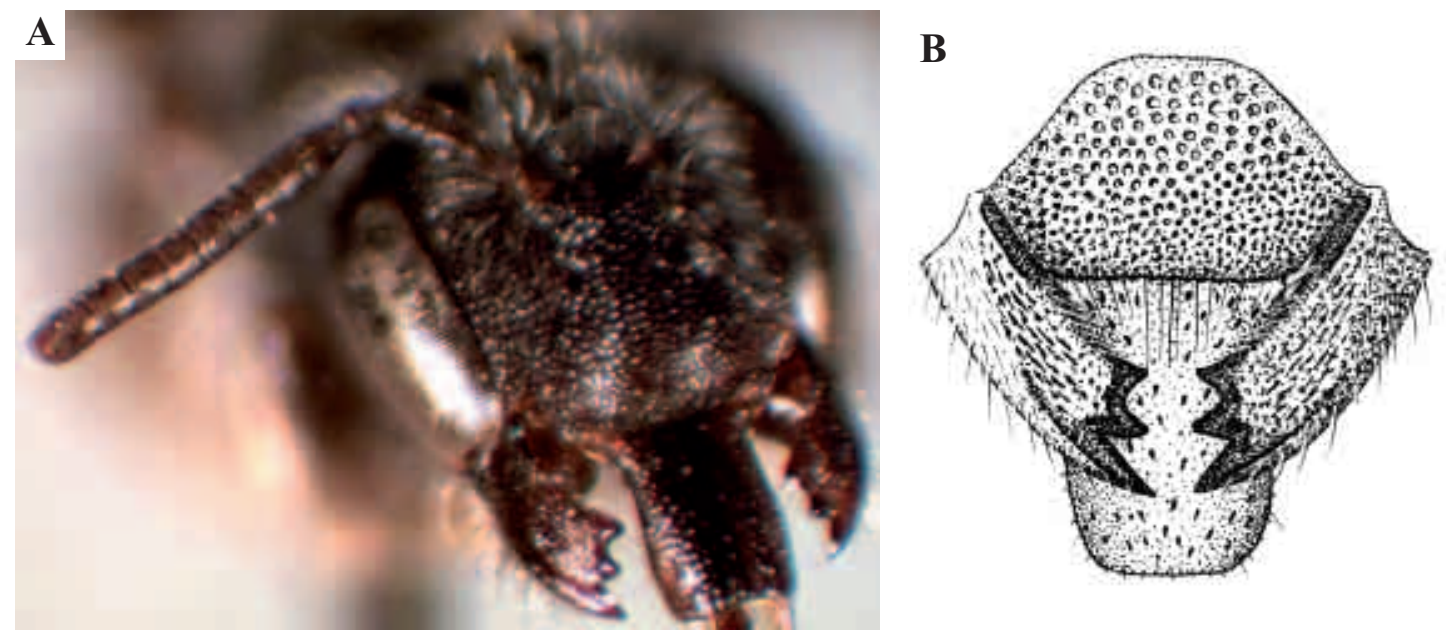

Fig. 4.- Hembra de Stelis breviuscula: Vista frontal de la cabeza (A); esquema del clípeo, el labro y las mandíbulas (B); vista lateral del labro y de la mandíbula (C).

Fig. 4.- Stelis breviuscula female: Head in front view (A); drawing of clypeus, labrum and mandibles (B); labrum and mandible in lateral view $(\mathrm{C})$.

reducido prácticamente a su área central, un estrecho surco horizontal o inclinado, profundo y brillante, con subdivisiones longitudinales más o menos homogéneamente dispuestas, a modo de una serie de grandes punteaduras u oquedades y que no existe en todas las especies.

El gáster (Figs. 2 y 11) es corto y grueso, sin escopa ventral en las $ᄋ$ 우, recurvado y excavado por debajo, sin espinas o dientes o sólo con una pequeña punta central en los $\sigma^{x} \sigma^{7}$, en los que la forma, la pubescencia y las distintas estructuras de los esternitos gastrales (Figs. 12A), como el peine central de cerdas del cuarto esternito (Figs. 12A, $13 \mathrm{~F}, 14 \mathrm{~A}, 14 \mathrm{~B}, 16 \mathrm{D}$, etc.), o las cápsulas genitales (Figs. 12B, 13G, 15C, etc.) son de valor taxonómico. En éstas lo es la forma del extremo de los gonocoxitos, su zona dilatada, que adquiere distintos aspectos en las diferentes especies (Figs. 12B, 14C, $15 \mathrm{D}$, etc.). En el gáster, y como es usual, se designa a terguitos y esternitos, abreviadamente, por su

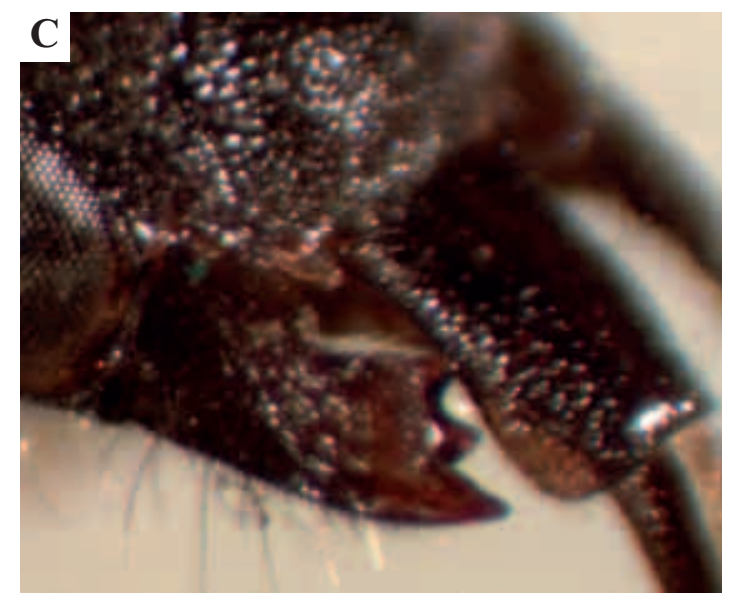

inicial, es decir, T y E, seguida de un subíndice que corresponde al ordinal del segmento gastral referido; por ejemplo, el tercer terguito se abrevia como $\mathrm{T}_{3} \mathrm{y}$ el quinto esternito como $\mathrm{E}_{5}$.

El tegumento presenta un punteado fuerte, incluso grosero, granulado en algunas zonas en ciertas especies, y puede ser negro o estar coloreado de amarillo en áreas más o menos extensas (Figs. 2 y 11). El color de la pubescencia varía desde el blanco al amarillo dorado.

\section{Resultados y discusión}

Especies ibéricas de Stelis Panzer, 1806

Stelis annulata (Lepeletier, 1841)

Stelis breviuscula Nylander, 1848

Stelis minuta Lepeletier \& Serville, 1825

Stelis nasuta (Latreille, 1809)

Stelis odontopyga Noskiewicz, 1926 

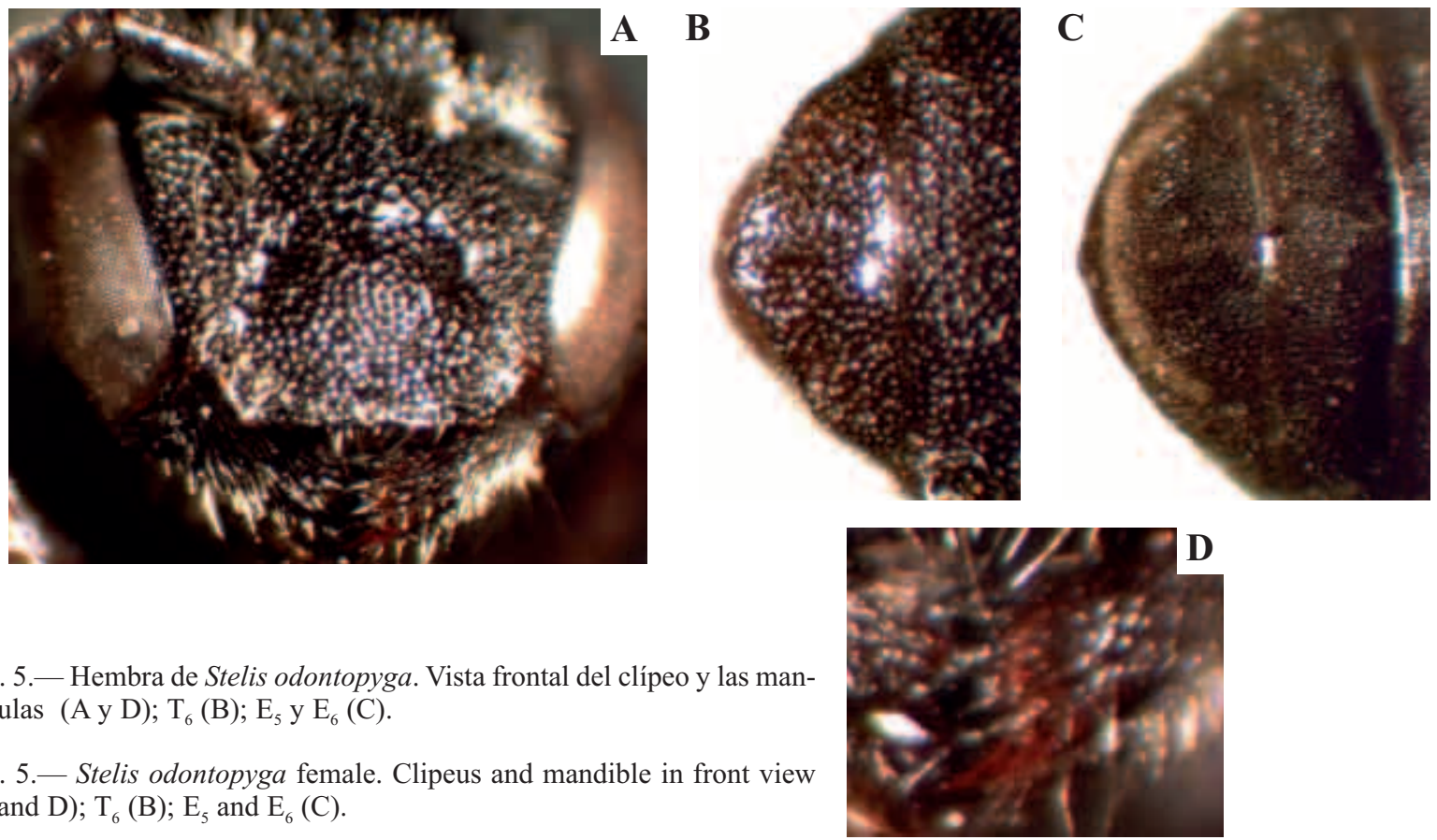

Fig. 5.- Hembra de Stelis odontopyga. Vista frontal del clípeo y las mandíbulas (A y D); $\mathrm{T}_{6}(\mathrm{~B}) ; \mathrm{E}_{5} \mathrm{y} \mathrm{E}_{6}(\mathrm{C})$.

Fig. 5.- Stelis odontopyga female. Clipeus and mandible in front view (A and D); $\mathrm{T}_{6}(\mathrm{~B}) ; \mathrm{E}_{5}$ and $\mathrm{E}_{6}(\mathrm{C})$.

muy burdo y denso hasta el borde distal, que es brillante y

Stelis ornatula (Klug, 1808)

Stelis phaeoptera (Kirby, 1802)

Stelis punctulatissima (Kirby, 1802)

Stelis signata (Latreille, 1809)

Stelis simillima Morawitz, 1876

\section{Clave de hembras}

1. Gáster uniformemente negro o castaño oscuro, sin manchas blancas o amarillas en el tegumento, a los lados de los terguitos (Figs. 2A y 2B). Patas negras u oscuras .......... 2

- Gáster no uniformemente negro o castaño oscuro, siempre tiene manchas amarillas o blanquecinas, grandes o pequeñas (Figs. 2C, 2D y 2E). Patas tanto negras como amarillas o rojizas

.. 6

2. Borde distal de los segmentos gastrales, en especial $T_{2}-T_{4}$ aclarado y pálido, desde blanquecino color hueso hasta acaramelado, translúcido (Fig. 2B)

- Borde distal de los segmentos gastrales oscuro, pardusco oscuro como mucho, aunque sea algo más claro que el resto (Fig. 2A)

3. Mandíbulas normales, no acodadas, levantadas ni dirigidas hacia delante. Clípeo (Fig. 3B) convexo, toscamente punteado y escotado en el borde apical; el punteado es tan denso como en la mitad inferior de la cara y en su escotadura central presenta un pequeño reborde o engrosamiento. Escutelo triangular, con punteaduras grandes, pero del mismo tamaño que las de la parte posterior del mesonoto (Fig. 3D). $\mathrm{T}_{6}$ amplio, ancho, acabado ligeramente en punta, alabeado y vuelto en esa zona en la que posee un punteado ligeramente engrosado. Longitud: 8-11 mm

S. punctulatissima

- Mandíbulas acodadas en la base, dirigidas hacia delante (muy patente en vista lateral). Clípeo plano, glabro y mate, con el borde apical recto y un punteado mucho menos denso que el de la mitad inferior de la cara. Escutelo triangular y cubierto de punteaduras enormes, mayores que las de la parte posterior del mesonoto (Fig. $3 \mathrm{E}$ ). $\mathrm{T}_{6}$ no arqueado hacia arriba en el borde distal, que es liso, pulido y casi sin punteado. Longitud: 9-10 $\mathrm{mm}$.....

S. simillima

4. Borde distal de los terguitos gastrales no pálido, aunque sea más aclarado y translúcido que el resto, y provisto encima de una visible faja de pubescencia corta y pálida (Fig. 2A). Labro muy alargado (Figs. 4A, 4B y 4C). Clípeo con el borde apical completamente recto o muy escasamente hundido, pero no engrosado (Figs. 4A y 4B). Distancia preoccipital corta, equivalente a $1 \varnothing$. Longitud: 4-6,5 mm ....

S. breviuscula

- Borde distal de los terguitos gastrales sin faja de pubescencia. Labro más corto. Borde apical del clípeo festoneado. Distancia preoccipital $>1 \varnothing$

.. 5

5. Distancia preoccipital $=2 \varnothing$. Tibias posteriores anchas $y$ robustas; en su cara dorsal llevan dos pequeñas puntas o dientes desiguales terminales, de los que el anterior es visiblemente mayor; las tibias, poseen pubescencia blanca y larga, sobresaliente, cuya longitud es superior o igual a la mitad de la anchura de la tibia. Borde apical del clípeo festoneado (Fig. 3A), ligeramente convexo, a veces escotado en el centro. Espacio entre los dientes mandibulares amplio, en U. Terguitos gastrales con punteado irregular, por lo menos, en la zona media. $\mathrm{T}_{6}$ subpentagonal. $\mathrm{E}_{6}$ de 

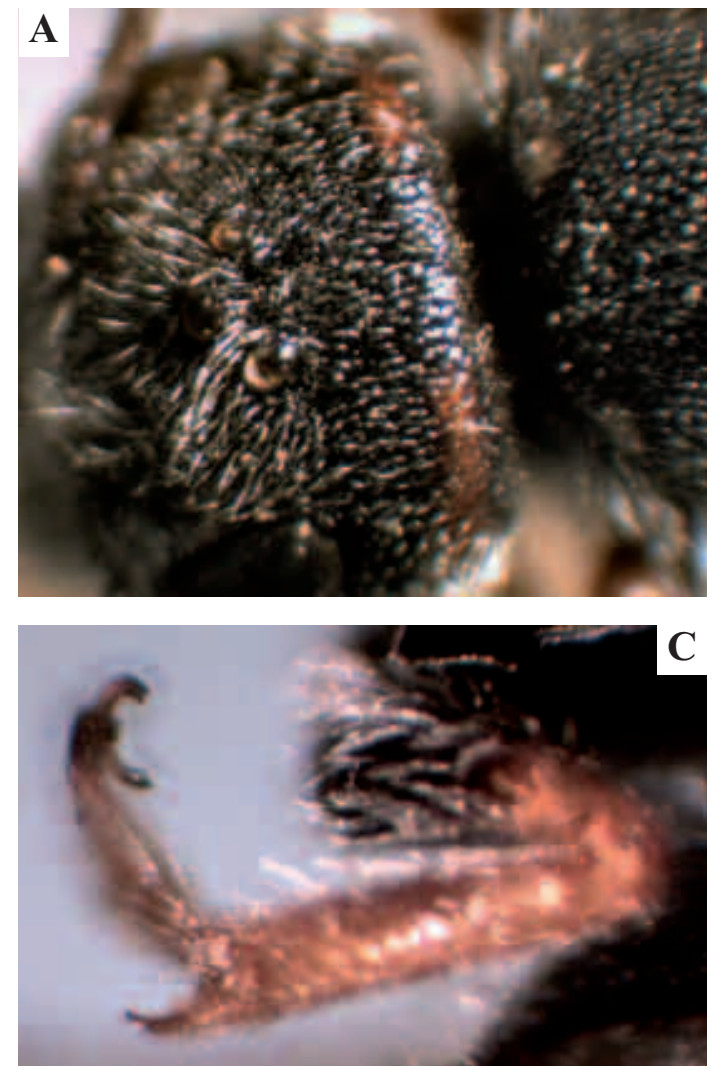

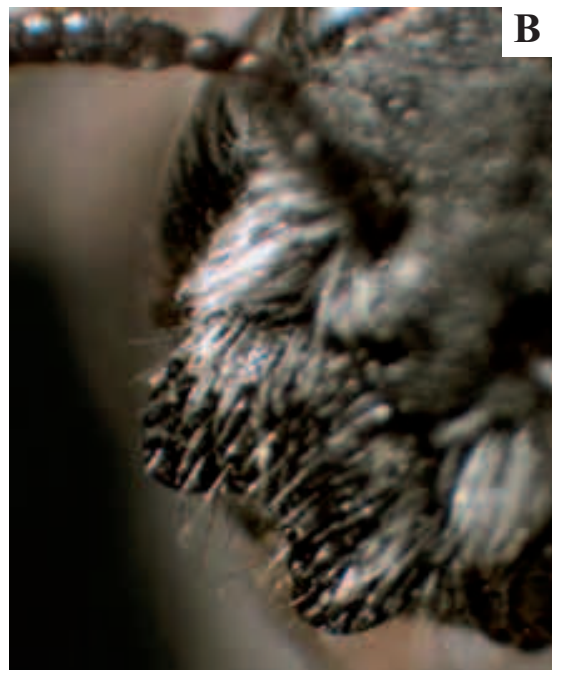

Fig. 6.- Hembra de Stelis nasuta: Campo ocelar (A); clípeo (B); tibia del primer par de patas (C).

Fig. 6.- Stelis nasuta female: Ocellar area (A); clypeus (B); fore leg tibia (C). contorno triangular. Longitud: 6,5-12 $\mathrm{mm}$

\section{S. phaeoptera}

- Distancia preoccipital equivalente a 1,5 Ø. Tibias posteriores normales; en su cara dorsal llevan dos pequeñas puntas o dientes terminales, casi iguales, y poseen pubescencia pálida muy corta e igualada, sin pelos sobresalientes; las tibias acaban oblicuamente en su cara ventral. Borde apical del clípeo festoneado, recto, no convexo (Fig. 5A). Espacio entre los dientes mandibulares estrecho, en V (Figs. 5A y 5D). Terguitos gastrales con punteado denso y uniforme. $\mathrm{T}_{6}$ subtriangular, con el borde distal alabeado (Fig. 5B). $\mathrm{E}_{6}$ de contorno semicircular (Fig. 5C). Longitud: 5,5-7 mm ......

S. odontopyga

6. Coloración del cuerpo negra y amarilla; gáster con bandas amarillas continuas o interrumpidas en el medio (Figs. 2C, $2 \mathrm{D}$ y $2 \mathrm{E}$ ). Patas castaño rojizas, amarillas o ambas cosas ....

- Coloración del cuerpo negra; sólo el gáster, en algunos terguitos, posee manchas pálidas, pequeñas y laterales, en ocre o a veces amarillo oscuro, como lunares (Figs. 11B y 11C)

... 9

7. Clípeo grande, convexo, muy característico, con el borde apical libre y muy escotado en la parte media, de modo que da lugar a dos lóbulos sobresalientes (Fig. 6B). Distancia preoccipital $=4 \varnothing$ (Fig. 6A). Tibias anteriores provistas de un diente distal interior, ganchudo, con forma de garra y mucho más largo que el exterior (Fig. 6C) (también existe en el segundo par, pero es algo menor). $\mathrm{E}_{6}$ subtriangular, muy esculpido, elevado en el centro, sobre todo en la región proximal, y acabado en una punta sobresaliente. $\mathrm{T}_{6}$ corto y ancho, con el margen distal denticulado, acabado en una hilera de púas. Coloración del gáster (Fig. 2D) negra a bandas amarillas discontinuas, normalmente con cuatro manchas por terguito, en $\mathrm{T}_{2}-\mathrm{T}_{4} \mathrm{y}$ dos en $\mathrm{T}_{1} \mathrm{y} \mathrm{T}_{5}$. El clípeo es negro y generalmente también $\mathrm{T}_{6}$. Longitud: 7-8,5 $\mathrm{mm}$............................................................. S. nasuta

- Clípeo hexagonal, sin el borde apical libre, ni escotado en su parte media, sino recto, más o menos festoneado. Distancia preoccipital $<4$ Ø. Tibias anteriores sin un largo diente distal interior, ganchudo y con forma de garra. $\mathrm{T}_{6}$ con un punteado tosco y profundo que le da aspecto granulado y rugoso, sobre todo en el borde distal, pero sin dar lugar a una hilera de púas. $\mathrm{E}_{6}$ más o menos groseramente punteado en toda su superficie, pero no elevado en un área diferenciada central. Coloración del gáster a bandas amarillas continuas o subdivididas sólo en dos por terguito (Figs. $2 \mathrm{C}, 2 \mathrm{D}$ y $2 \mathrm{E}$ ). Clípeo amarillo en mayor o menor extensión, nunca completamente negro 8

8. Distancia preoccipital $=3 \varnothing$; esa zona posee el mismo punteado denso que el mesonoto. Zona inferior de las antenas de color castaño; $\mathrm{A}_{3} \mathrm{y}_{4}$ de tamaño semejante al resto de los flagelómeros. Clípeo con el borde apical recto, pero claramente denticulado, con dentículos que son como púas (Fig. 7B) y tapado este borde por pelos largos dorados. Mandíbulas grandes, convexas, con tres dientes fuertes y 

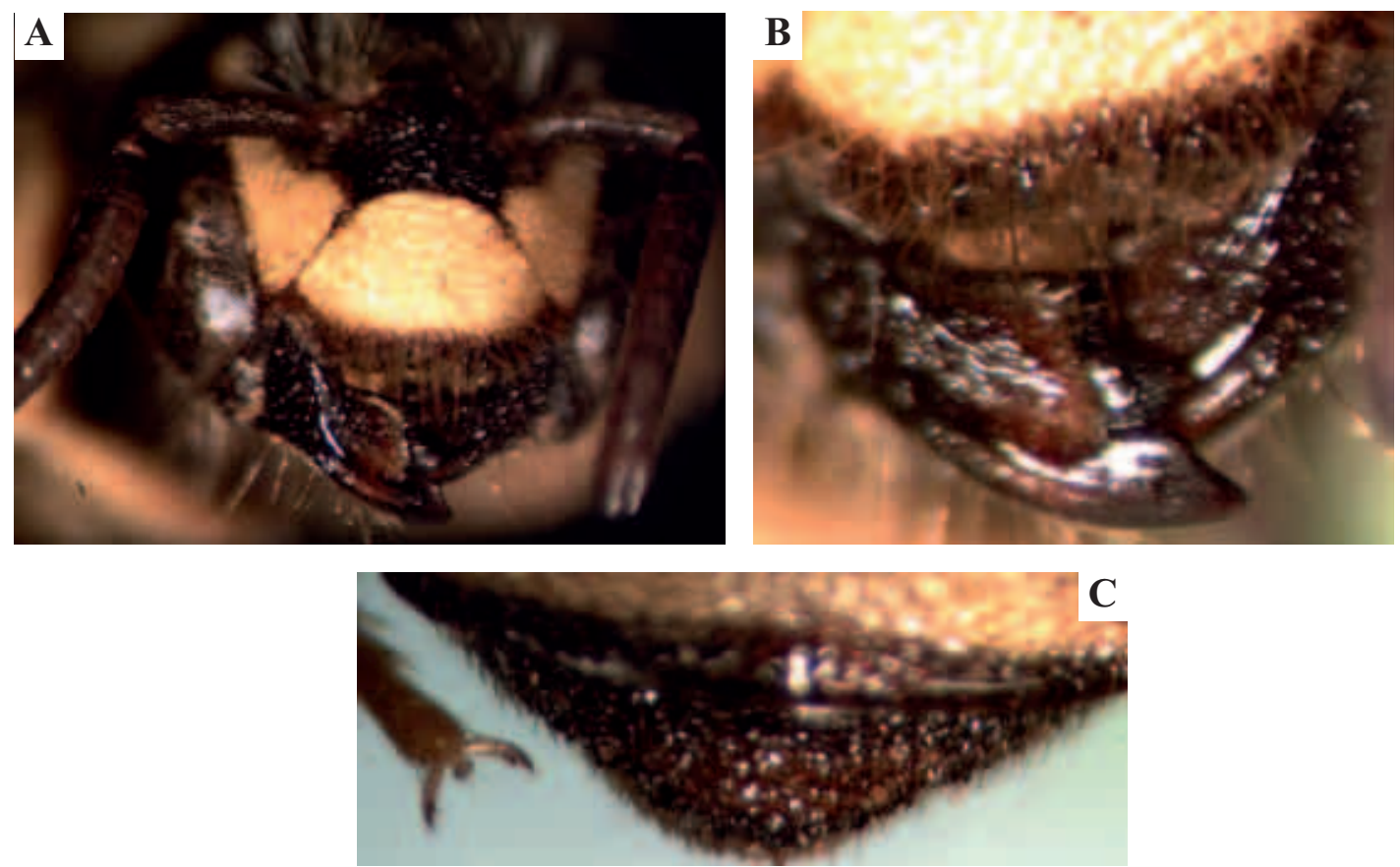

Fig. 7.- Hembra de Stelis annulata: Vista frontal de la cabeza (A), del clípeo y de las mandíbulas (B); $\mathrm{T}_{6}(\mathrm{C})$.

Fig. 7.- Stelis annulata female: Head in front view (A), right mandible and clypeus (B); $\mathrm{T}_{6}(\mathrm{C})$.

bien diferenciados, mayor el apical (Figs. 7A y 7B). $\mathrm{T}_{6}$ triangular, romo (Fig. $7 \mathrm{C}) . \mathrm{E}_{6}$ triangular. Coloración del gáster a bandas amarillas que ocupan casi todo el ancho del terguito y pueden ser continuas o separadas en el centro (Fig. 2C). Clípeo amarillo (Figs. 7A y 7B). Longitud: 8,5$11 \mathrm{~mm}$ S. annulata

- Distancia preoccipital $<2 \varnothing$. Antenas muy cortas, ya que lo son $\mathrm{A}_{3} \mathrm{y} \mathrm{A}_{4}$; en conjunto, la suma de sus longitudes casi no llega a la longitud de $\mathrm{A}_{5}$ (Fig. 8A). Mandíbulas robustas, pero estrechas, con el borde casi liso y recto, en el que sólo sobresale el diente apical, largo y agudo y, muy poco o nada, según los ejemplares, el segundo (Fig. 8B). Clípeo hexagonal, con el borde apical recto, festoneado o granulado, no denticulado (Fig. 8C). $\mathrm{T}_{6}$ muy corto y ancho, no acabado en punta y con el borde distal prácticamente paralelo al proximal. $\mathrm{E}_{6}$ aplanado, redondeado, de contorno casi semicircular. Coloración del gáster (Fig. 2E) a bandas amarillas más o menos anchas, que se llegan a unir en $\mathrm{T}_{4} \mathrm{y} \mathrm{T}_{5}$, pero suelen dejar un espacio negro central en los anteriores; $\mathrm{T}_{6}$ generalmente negro u oscuro, y en algún ejemplar casi $\mathrm{T}_{5}$ también. El clípeo puede ser completamente amarillo o poseer proporciones variables de color negro, sin llegar a serlo del todo. Longitud: 5,5-7 $\mathrm{mm}$

S. signata

9. Mandíbulas (Figs. 9A y 9B) tridentadas, muy características, fuertes y robustas, aunque se estrechan desde la base y más aún en el centro del margen externo, donde hay una constricción inferior; su superficie no es plana, sino acoda- da en el medio, por el gran desarrollo de una quilla oblicua, casi en ángulo recto, que diagonalmente la recorre desde el cóndilo superior hasta el inicio del diente apical (Fig. 9B). En vista dorsal, el contorno del borde libre de ambas mandíbulas forma un semicírculo. Distancia preoccipital equivalente justo a $2 \varnothing$. Borde apical del clípeo suavemente redondeado, recto en el centro, brillante y ligeramente engrosado (Fig. 9A). Basitarsos posteriores engrosados progresivamente desde la zona proximal, que es la más estrecha, hasta el extremo (Fig. 9C). Terguitos gastrales, hasta $\mathrm{T}_{3} \circ \mathrm{T}_{4}$, con manchas laterales pequeñas (Fig. 11C), desiguales las de los distintos terguitos, amarillentas, ocres, y más o menos redondeadas; suelen ser menores las de $\mathrm{T}_{1}$ y más alargadas las otras (en algunos ejemplares existen sólo en $T_{2}$ y son muy empalidecidas y pequeñas en $T_{3}$ ). $T_{6}$ subtriangular, ligeramente arqueado hacia arriba en el borde distal. Longitud: 7-8 $\mathrm{mm}$

S. ornatula

- Mandíbulas sin constricción en el margen externo, provistas de una quilla incompleta, casi paralela a dicho margen, desarrollada sólo hasta la zona media. Distancia preoccipital equivalente a 1,5 Ø. Borde apical del clípeo brillante, recto, levemente engrosado y, a veces, deprimido en el centro. Basitarsos posteriores uniformemente engrosados (Fig. 10A). Terguitos gastrales negros con manchas amarillentas pequeñas a los lados en los dos o tres primeros (Figs. 10B y 11B). $\mathrm{T}_{6}$ subpentagonal (Fig. 10B). Longitud: 4-7 mm .. 

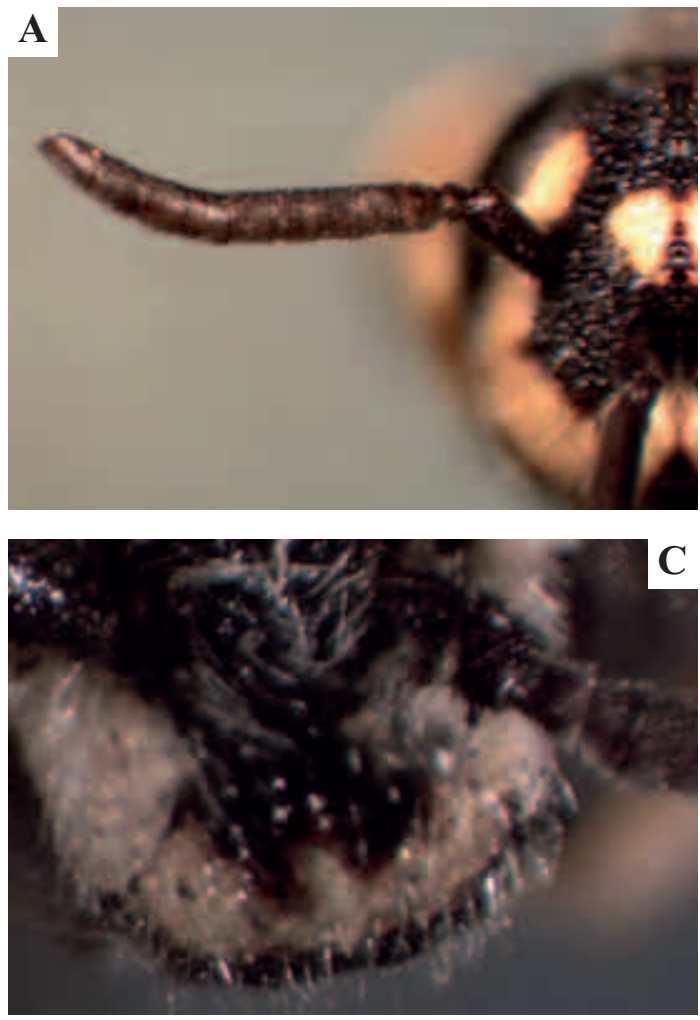

\section{Clave de machos}

1. Gáster uniformemente negro o castaño oscuro, sin manchas blancas o amarillas a los lados de los terguitos (Figs. 2A, 2B y 11A). Patas negras u oscuras

2

- Gáster no uniformemente negro o castaño oscuro, siempre con manchas blancas o amarillas, pequeñas o grandes (Figs. 2D, 2E, 11A y 11C). Patas tanto negras como amarillas o rojizas

.. 6

2. Borde distal de los segmentos gastrales, en especial $T_{1}-T_{4}$, aclarado y pálido, desde blanquecino o color hueso hasta acaramelado, translúcido (Fig. 2B y 11A)

- Borde distal de los segmentos gastrales oscuro, pardusco, castaño como mucho, aunque aparezca más claro que el resto (Fig. 2A)

3. Mandíbulas como en la hembra, no levantadas ni dirigidas hacia delante (Fig. 3C). Clípeo, también semejante al de la hembra (Fig. 3B), escotado en el centro del borde apical y con punteado denso, como el de las zonas laterales de la cara. Tibias posteriores con dos espinas distales de igual tamaño y espolones delgados y no recurvados. $\mathrm{E}_{3}$ escotado en la base en una zona central, que presenta pelos largos, y normalmente no llega a tener forma semicircular. $\mathrm{E}_{4}$ casi plano en la zona media, emergido en el centro del borde distal en un saliente, pequeño, con forma trapezoidal, que sirve de base a un peine de cerdas corto e igualado (Fig.12A). $\mathrm{E}_{6}$ cóncavo en una banda lineal central (Fig.12A). $\mathrm{E}_{8}$ pentagonal, no escotado en el extremo distal (Fig. 12D). Resto de los esternitos y la genitalia como en

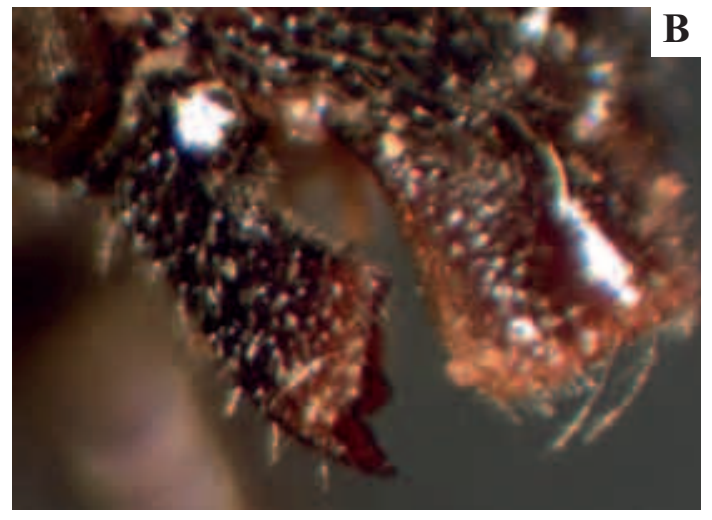

Fig. 8.- Hembra de Stelis signata: Antena derecha (A); mandíbula derecha y labro (B); clípeo (C).

Fig. 8.- Stelis signata female: Right antenna (A); right mandible and labrum (B); clypeus (C).

las Figs. 12A, 12B y 12C. Existen en los terguitos gastrales discretas bandas laterales distales de pelos blancos. Longitud: 6-9 mm ............................ S. punctulatissima

- Mandíbulas aplanadas y levantadas hacia arriba (Fig. 13A). Clípeo plano, mate (Fig. 13A), esculpido a base de grandes punteaduras, pero éstas son menos abundantes que a los lados de la cara. En general, el punteado de todo el cuerpo está formado por puntos muy grandes (Fig. 13B), en especial los del escutelo, que son mayores que los del mesonoto (Fig. 3E). Tibias posteriores con dos espinas desiguales y unos espolones gruesos y recurvados (Figs. 13C y 13D). $\mathrm{E}_{3}$ provisto en la base de una zona central diferenciada, escotada, en forma casi semicircular, rellena de pubescencia blanca convergente (Figs. 13F y 14A). E muy excavado en la parte media, donde existen pelos verticales; en el borde, el peine de cerdas es grande, de contorno rectangular, pero arqueado y hundido, cóncavo en la zona central (Figs. 13F y 14A). $\mathrm{E}_{6}$ se halla discretamente excavado en el centro y esa área es amplia y redondeada, no una banda lineal (Fig. $13 \mathrm{~F}$ y $14 \mathrm{~A}$ ). $\mathrm{E}_{8}$ pentagonal, escotado en el extremo distal (13E y 14D). Resto de los esternitos y gonocoxitos de la genitalia como en las Figuras $13 \mathrm{~F}, 13 \mathrm{G}, 13 \mathrm{H}$ y $14 \mathrm{C}$. Longitud: 8-10 $\mathrm{mm}$

S. simillima

4. Borde distal de $\mathrm{T}_{1}-\mathrm{T}_{4}$ con una banda de pubescencia corta y pálida, más visible desde los lados (Fig. 2A). Distancia preoccipital $=1 \varnothing . \mathrm{T}_{7}$ recto en el extremo posterior (Fig. 14E). $\mathrm{E}_{3}$ amplio, con el borde distal recto, del que sale una amplia banda de largas sedas blanquecinas. $\mathrm{E}_{4}$ con el borde distal ligeramente ondulado, saliente en la zona central; el 

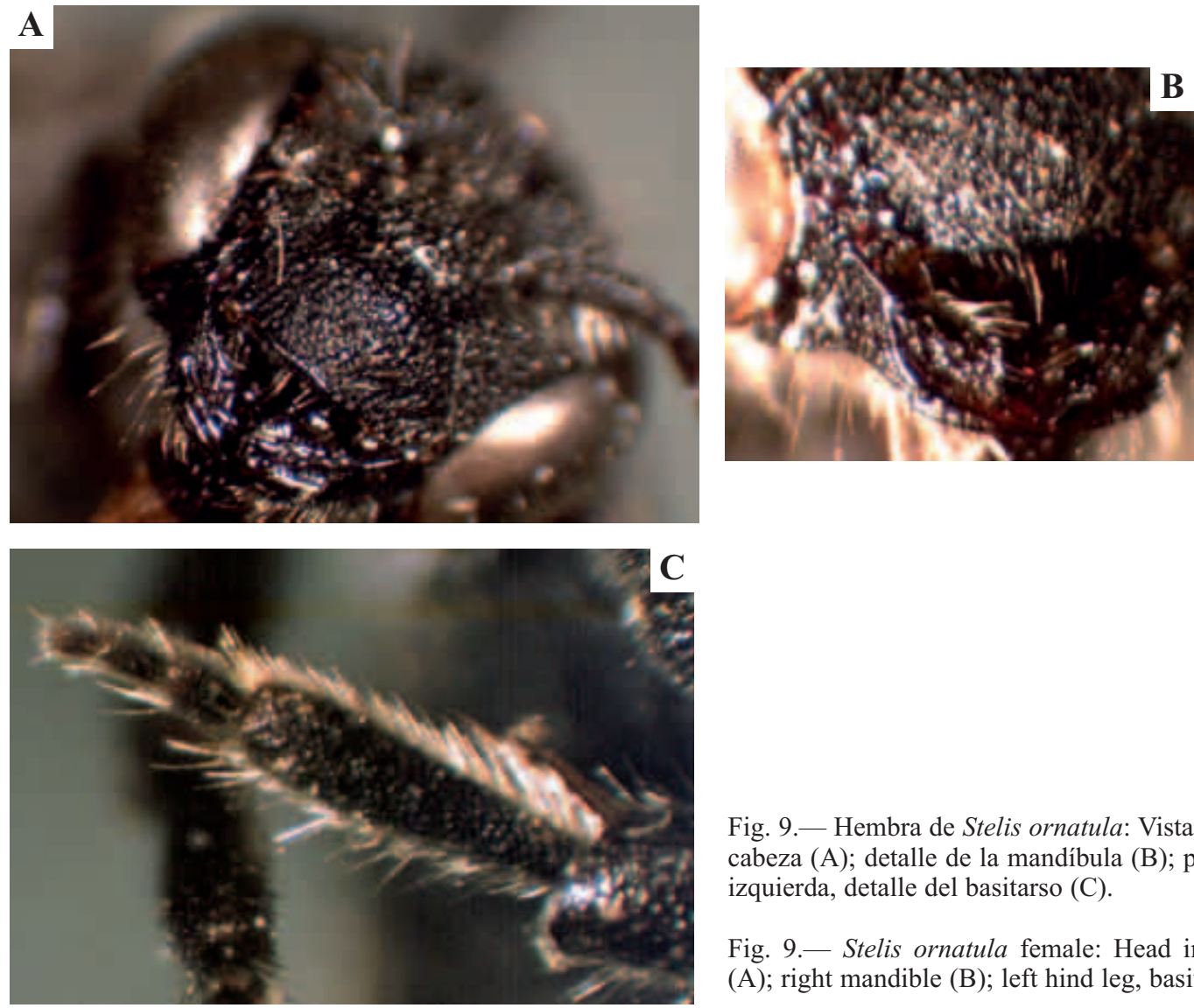

Fig. 9.- Hembra de Stelis ornatula: Vista frontal de la cabeza (A); detalle de la mandíbula (B); pata posterior izquierda, detalle del basitarso (C).

Fig. 9.- Stelis ornatula female: Head in front view (A); right mandible (B); left hind leg, basitarsus (C).

peine de cerdas es triangular y romo y lleva a los lados largas sedas blanquecinas y convergentes. $\mathrm{E}_{6}$ también saliente en el borde distal, excavado en el centro de su superficie, pero no muy cóncavo (Figs. 14B y 14E). Extremo de los gonocoxitos aplanado, de contorno más bien trapezoidal, casi rectangular en vista inferior, como paletas. Longitud: $5-5,5 \mathrm{~mm}$

S. breviuscula

- Terguitos sin bandas distales de pubescencia, normalmente sólo con pelos aislados. Distancia preoccipital $>1 \varnothing$. Esternitos gastrales y extremo de los gonocoxitos de otro modo 5

5. Borde distal de $T_{7}$ recto, no acabado en punta. Distancia preoccipital equivalente a $2 \varnothing$. Tibias posteriores con pubescencia de longitud variable, no igualada. Basitarso posterior con anchura decreciente hacia el ápice. $E_{3}$ plano y liso, sin escotadura en el extremo posterior, que es más bien saliente, y presenta pelos largos, en disposición convergente. También son convergentes las sedas del borde distal de $\mathrm{E}_{4}$ (Fig. 15A); en este esternito (Figs. 15A y 15B) es típica la pubescencia corta y blanca de su superficie, dispuesta en el centro y en dos áreas circulares laterales; el peine de cerdas central es grande, arqueado y sobresaliente, convexo y redondeado, en vista frontal, y doblado, dispuesto en dos planos, en vista superior. $\mathrm{E}_{6}$ aparece excavado en una zona central longitudinal (Fig. 15A) y redondeado en el borde, no acabado en punta. $\mathrm{E}_{7}$ corto, ancho y casi subdividido en dos (Fig, 15G). $\mathrm{E}_{8}$ romo en el extremo distal (Figs. 15E y 15F). Genitalia (Figs. 15C y 15D) con los gonocoxitos poliédricos en el extremo, paralelepipédicos. Longitud: 6-7,5 mm ............S. phaeoptera

- Borde distal de $T_{7}$ adelantado en una pequeña punta en la zona media, perceptible también en vista ventral (Figs. 16A, 16B y 16C). Distancia preoccipital equivalente a 1,5 $\varnothing$. Tibias posteriores con pubescencia corta e igualada. Basitarso posterior con anchura constante, excepto justo en la base. $\mathrm{E}_{3}$ muy amplio, escotado en el centro y con grandes flecos pálidos finales que tapan completamente a $\mathrm{E}_{4}$ (Fig. 16D), cuyo peine de cerdas es corto, pero extendido hacia los lados. $\mathrm{E}_{6}$ (Figs. 16C y 16D) muy excavado, cóncavo en toda la superficie central, de modo que tal concavidad ocupa la mayor parte del esternito, excepto los lados. Longitud: 5,5-6,5 mm

S. odontopyga

6. Coloración negra y amarilla, gáster con grandes manchas amarillas, a bandas, como la hembra (Figs. 2C, 2D y 2E). Patas castaño rojizas, amarillas o ambas cosas ….......... 7

- Coloración negra, sólo el gáster posee manchas ocres o en amarillo oscuro, pequeñas, laterales en los terguitos, como en la hembra (Figs. 11B y 11C). Patas negras

9

7. Tibias del primer par de patas provistas de un diente final interior grande, ganchudo, con forma de garra, y mucho 

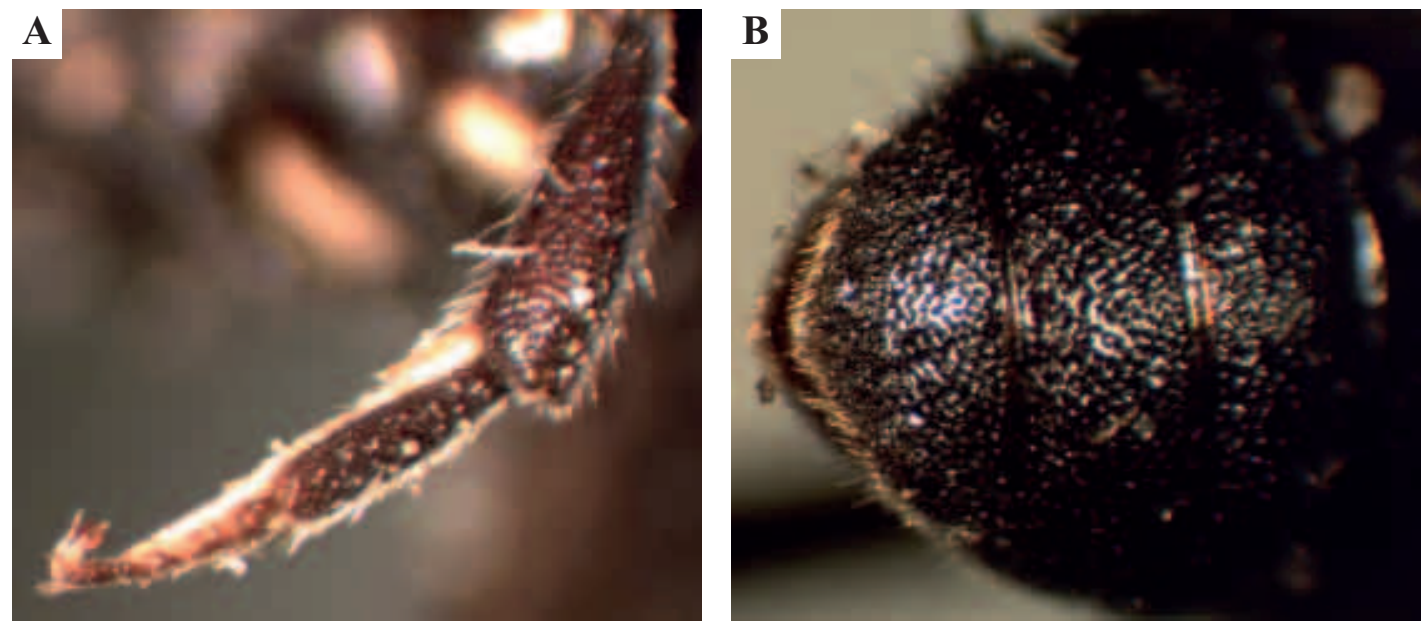

Fig. 10.- Hembra de Stelis minuta: pata posterior izquierda, detalle del basitarso (A) y últimos terguitos gastrales (B).

Fig. 10. - Stelis minuta female: Left hind leg, basitarsus (A); last gastral terga (B).

más largo que el exterior, como en la hembra (Fig. 6C). Clípeo grande, convexo, muy desarrollado y con el borde distal libre bilobulado, semejante al de la hembra (Fig. 6B), pero menos marcado. Antenas de color negro a negro pardusco. Distancia preoccipital $\geq 3 \varnothing$. Área central del propodeo no desarrollada. $\mathrm{T}_{6}$ y $\mathrm{T}_{7}$ acabados en una punta central brillante. Coloración del tegumento como en la hembra (Fig. 2D). Longitud 5,5-8 mm ............. S. nasuta

- Tibias del primer par de patas con los dos dientes del extremo cortos y casi de la misma longitud. Clípeo no prominente, sin el borde distal libre y sin dar lugar a dos lóbulos. Área central del propodeo desarrollada. $\mathrm{T}_{6}$ no acabado en una punta central, aunque $\mathrm{T}_{7}$ sí puede hacerlo ..........8 8

8. Distancia preoccipital $<2 \varnothing$. Antenas cortas, al serlo $\mathrm{A}_{3} \mathrm{y}$ $\mathrm{A}_{4}$ (Fig. 17A), oscuras, negras o castañas. Área central del propodeo situada en un plano muy bajo, hacia la mitad de la superficie vertical y constituida por un surco de fosetas brillantes y seriadas; las laterales, que son mayores, pueden llegar a ser cuadrangulares. Clípeo hexagonal, como en la hembra (Figs. 8C y 17A), con el borde apical recto, festoneado o granulado, no denticulado. $\mathrm{T}_{6}$ corto (Figs. 17B y $17 \mathrm{C}$ ), muy fuerte y toscamente punteado, pero con el borde distal recto, rematado por un filo liso y brillante; en la zona central de su superficie suele aparecer una línea longitudinal en relieve, especialmente en la mitad distal del terguito, normalmente lisa y brillante, pero, en ciertos ejemplares, puede llegar a formar una quilla y/o recorrer la superficie de base a extremo. $\mathrm{T}_{7}$ triangular, provisto en el borde distal de una punta aguda central (Figs. 17B y 17C). Superficie de $\mathrm{E}_{2}$ lisa, sin ningún repliegue. $\mathrm{E}_{5}$ escotado en la zona media. $\mathrm{E}_{6}$ saliente, redondeado y convexo en el borde distal; este esternito, a diferencia de otras especies, es aplanado, no hundido o excavado en el centro. Peine de cerdas de $\mathrm{E}_{4}$ corto, recortado, y con las cerdas laterales ligeramente oblicuas, por lo que el contorno resulta trape- zoidal. Extremo de los gonocoxitos de forma triangular (Figs. 17B y 17C). Longitud: 5,5-6 mm ......... S. signata - Distancia preoccipital equivalente a $3 \varnothing$. Antenas castaño rojizas por debajo. El área central del propodeo sólo es ligeramente horizontal y acanalada a los lados, el resto es una superficie inclinada, casi vertical, provista de punteaduras grandes irregularmente dispuestas en varias filas, pero no como fosetas seriadas en una fila. Clípeo denticulado, parecido al de la hembra. Borde de $\mathrm{T}_{7}$ acabado en tres salientes romos. Superficie de $\mathrm{E}_{2}$ provista de un amplio repliegue de contorno ligeramente semicircular. $\mathrm{E}_{5}$, en el borde distal, profundamente escotado, en $\mathrm{V}$. $\mathrm{E}_{6}$ cóncavo en el centro. Peine de $\mathrm{E}_{4}$ estrecho, más largo que ancho, con los lados ligeramente divergentes. Gonocoxitos no triangulares, como paletas, con el borde distal ondulado. Longitud: 7-8,5 mm

\section{S. annulata}

9. $\mathrm{E}_{3}$ ligeramente saliente en el borde distal, no hendido en la zona media (Fig. 18A). El peine central de cerdas de $\mathrm{E}_{4}$ (Figs. 18A y 18B) es pequeño, igualado, como un pincel, y está situado por delante de un área semicircular central proximal (emergente desde la membrana intersegmentaria), cubierta, a su vez, de pubescencia corta y pálida, que no lo tapa, así como tampoco lo hace la faja de $\mathrm{E}_{4}$, interrumpida en esa zona. Extremo final de $\mathrm{T}_{7}$ redondeado, no acabado en una punta (Fig. 18A). Mandíbulas como en la hembra (Figs. 9A y 9B), acodadas y, en vista dorsal, con una patente quilla en ángulo casi recto. Manchas del gáster (Fig. 11C) pequeñas y laterales y variables en número, ya que habitualmente aparecen en $T_{1}-T_{4}$, pero pueden reducirse y quedar sólo en $\mathrm{T}_{2}$. Pubescencia de las tibias posteriores corta, la longitud de los pelos no llega a la mitad de la anchura máxima de la tibia. Genitalia como en la figura 18C. Longitud: 6-6,5 mm S. ornatula

- $\quad \mathrm{E}_{3}$ (Fig. 19C) escotado en el borde distal, en la zona media; la faja de pubescencia pálida que emerge en el esternito, y se 

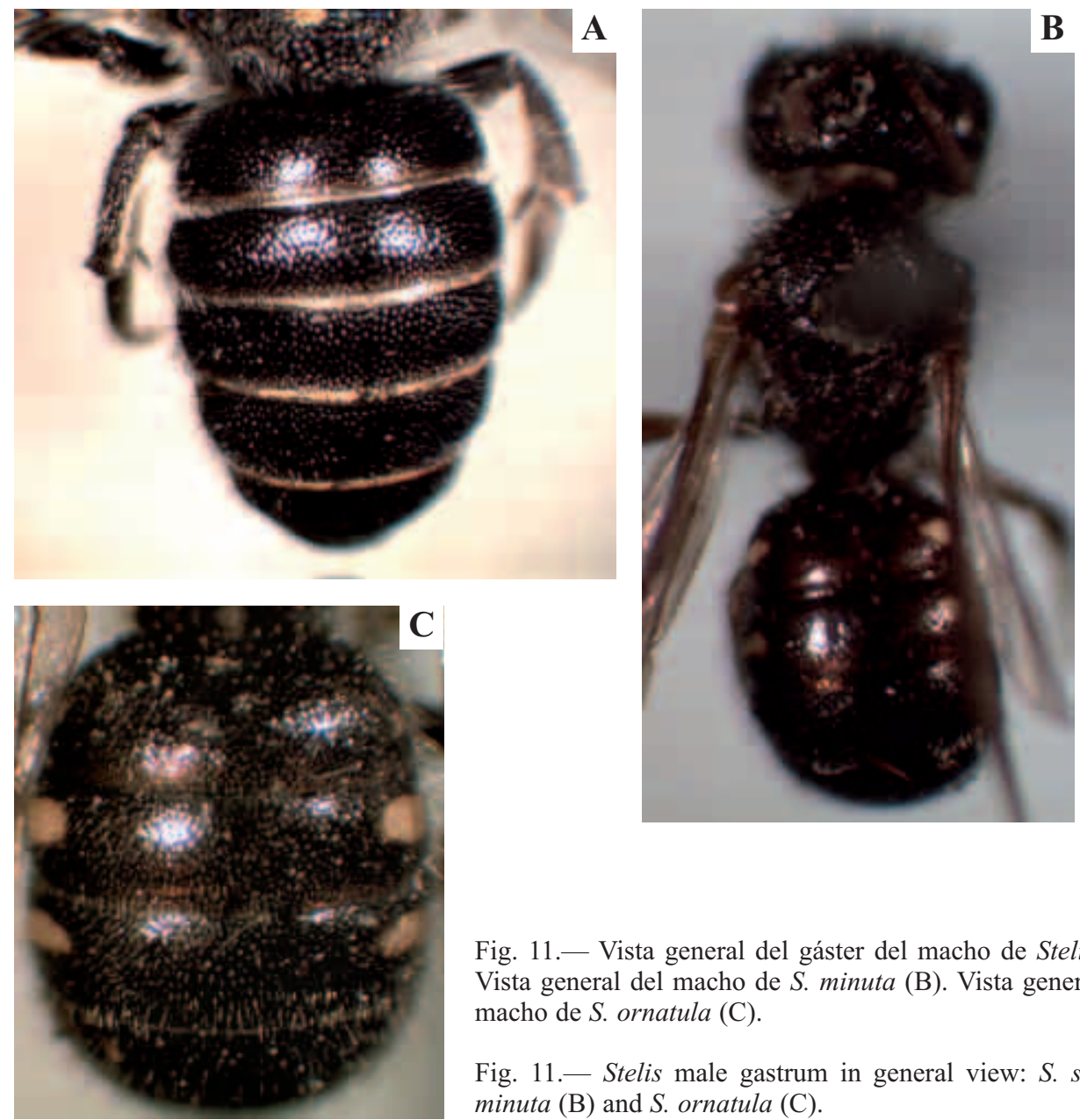

Fig. 11.- Vista general del gáster del macho de Stelis simillima (A). Vista general del macho de $S$. minuta (B). Vista general del gáster del macho de $S$. ornatula (C).

Fig. 11.- Stelis male gastrum in general view: S. simillima (A), $S$. minuta (B) and S. ornatula (C).

halla delante, es especialmente densa y larga en esa área; también lo es la de $\mathrm{E}_{4}$, que enmarca a cada lado el peine central de cerdas y casi lo oculta (Fig. 19C); éste es pequeño, con las cerdas centrales algo más largas, lo que le distingue del peine de $\mathrm{E}_{4}$ de Stelis ornatula, más recortado e igualado. Extremo final de $T_{7}$ acabado en una punta central (Figs. 19B). Mandíbulas aplanadas (Fig. 19A). Manchas del gáster como en la Figura 11B. Pubescencia de las tibias posteriores larga, la longitud de los pelos sobrepasa la mitad de la anchura máxima de la tibia. Longitud: 5-5,5 $\mathrm{mm}$ S. minuta

\section{Datos nuevos de las especies ibéricas del género Stelis}

\section{Stelis annulata (Lepeletier, 1841)}

Especie mediterránea (Ornosa et al., 2008), citada en la fauna ibérica en las provincias de Barcelona, Huesca, Teruel y Valladolid (Dusmet, 1921; Warncke, 1992).
El holotipo (1 오, Valladolid, 14-VI-1892, Martínez Escalera leg., Colección Dusmet, MNCN) y único individuo existente de Stelis hispanica Dusmet, 1921, fue pasado a sinonimia de Stelis annulata por Warncke (1992) certeramente, aunque, aparentemente, sin ver el ejemplar. Este individuo (Fig. 2C), pertenece sin duda a Stelis annulata, a pesar de ciertas diferencias observables (en el tamaño, coloración, escultura, desarrollo de las mandíbulas o del occipucio), sin duda debidas al hecho que el propio Dusmet (1921) señalaba "esta hembra tiene un Stylops, que aparece bajo el cuarto segmento ventral" y que aún puede observarse.

NuEVOS REgistros:

- Huesca: Hecho, 28-VIII-1932, 1 ㅇ, Dusmet leg., Colección Dusmet, MNCN; identificada por Dusmet como Stelis signata, es Stelis annulata. 

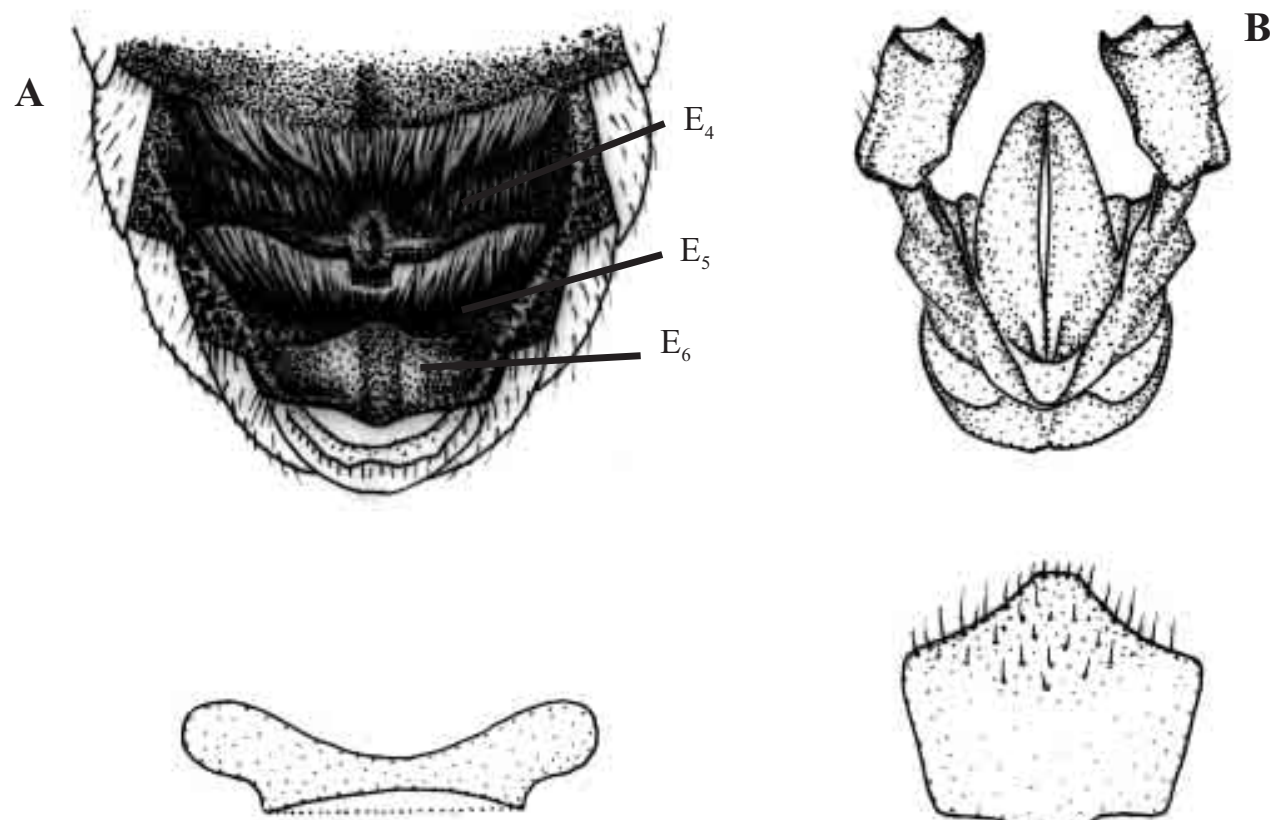

C

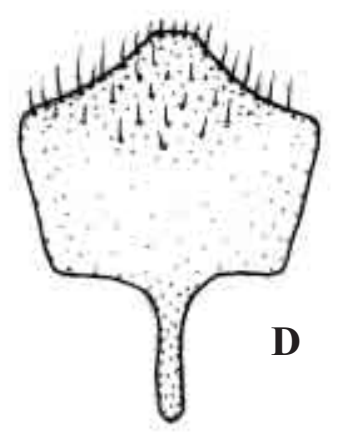

Fig 12. - Macho de Stelis punctulatissima: Vista ventral esquemática del gáster (A), genitalia (B), $\mathrm{E}_{7}(\mathrm{C})$ y $\mathrm{E}_{8}(\mathrm{D})$.

Fig 12.- Stelis punctulatissima male: Gastrum in ventral view (A), genitalia (B), $\mathrm{E}_{7}(\mathrm{C})$ and $\mathrm{E}_{8}(\mathrm{D})$.

Stelis signata (Latreille, 1809)

Especie paleártica occidental, citada en la Península Ibérica en Portugal: Angeiras, Coimbra, Estoril, Figueira da Foz, Sines (Diniz, 1989) y España: Ávila, Barcelona, Madrid, Segovia, Valencia y Zaragoza (Bofill, 1905; Dusmet, 1921; Espeso \& Gayubo, 1988). Las citas actuales extienden su distribución ibérica.

NUEVOS REGISTROS:

- Ávila: Guisando, 1 ㅇ, MNCN. Barcelona: Centellas, Cataluña, 18-VII-1920, 1 오, Mas de Xaxars leg., Stelis signata Cabrera det., MNCN. Murcia: Murcia, 1 \&, 25-VI-1922, Andréu leg., Stelis signata Latr. (caligrafía de Dusmet), MNCN. Zaragoza: Pina de Ebro, 12-VIII-1990, 1 오, J. Blasco leg., USAL.

No corresponden a Stelis signata (además del ejemplar de Hecho -Huesca- consignado anteriormente):

$1 \sigma^{7}$, Ávila: Guisando, Colección Dusmet (de la serie de Stelis signata), MNCN; es Anthidiellum strigatum (Panzer, 1805).

$10^{7}$, Ávila: Navalperal, VII-1904, Escalera leg., Colección Dusmet, (de la serie de Stelis signata), MNCN; es Anthidiellum strigatum.

$10^{7}$, Madrid: El Pardo, Dusmet, 24-VI-36, Colección Dusmet (de la serie de Stelis signata), MNCN; es Anthidiellum strigatum.
$10^{7}$, sin localidad, 27223 (sic), Colección Dusmet, identificado como Stelis signata Latr. (caligrafía de Dusmet), MNCN; es Pseudoanthidium lituratum (Panzer, 1801).

$10^{7}$, S. Fer., Colección Dusmet (de la serie de Stelis signata) MNCN; es Pseudoanthidium lituratum.

Stelis minuta Lepeletier \& Serville, 1825

Especie paleártica occidental, citada en montañas europeas (entre $43^{\circ}$ y $60^{\circ}$ de latitud) (Warncke, 1992) y en el sur "hasta Pirineos" y norte de Italia, Grecia, Macedonia, Turquía y Armenia, y en el norte de África (en montañas de Argelia y Marruecos) (Warncke, 1992; Comba \& Comba, 2001; Ornosa et al., 2008). Su presencia en España, basada en una antigua cita de Barcelona, fue rechazada por el mismo Dusmet (1921), aunque repetida por Ceballos (1956) y otros autores, presumiblemente por un error. Su localización actual en Sierra Nevada, en la provincia de Granada, amplía notablemente su distribución ibérica conocida y confirma el carácter orófilo de esta especie en nuestro territorio. 

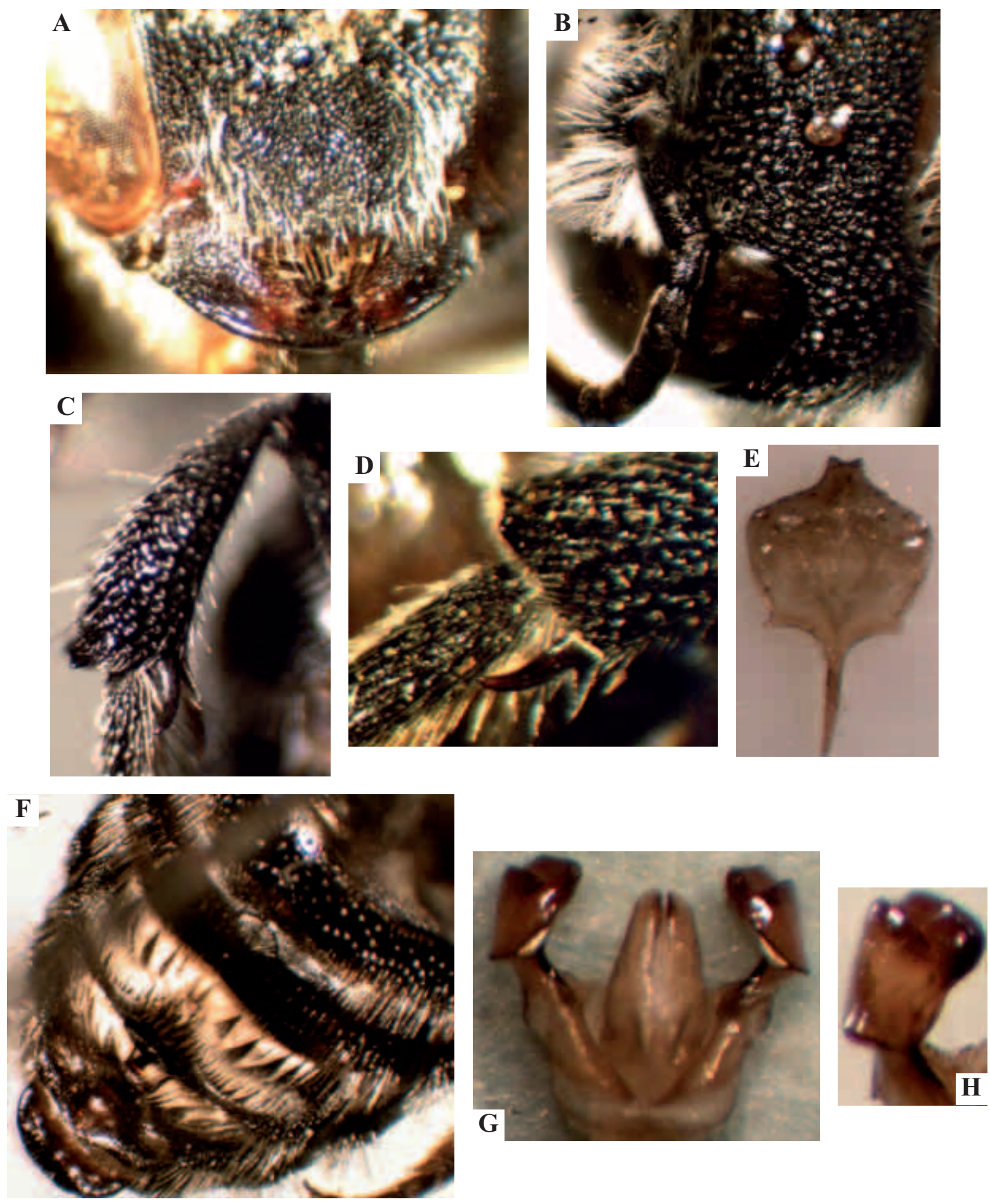

Fig 13.- Macho de Stelis simillima: Vista frontal (A) y vista dorsal (B) de la cabeza; tibia del tercer par de patas (C) y (D); $\mathrm{E}_{8}$ (E); vista ventral de los esternitos gastrales $(\mathrm{F})$; genitalia $(\mathrm{G})$ y porción terminal del gonocoxito izquierdo $(\mathrm{H})$.

Fig 13.- Stelis simillima male: Head in front (A) and dorsal (B) views; hind leg tibia (C) and (D); $\mathrm{E}_{8}$ (E); gastral sterna in ventral view $(\mathrm{F})$; genitalia $(\mathrm{G})$ and left gonocoxite terminal portion $(\mathrm{H})$. 

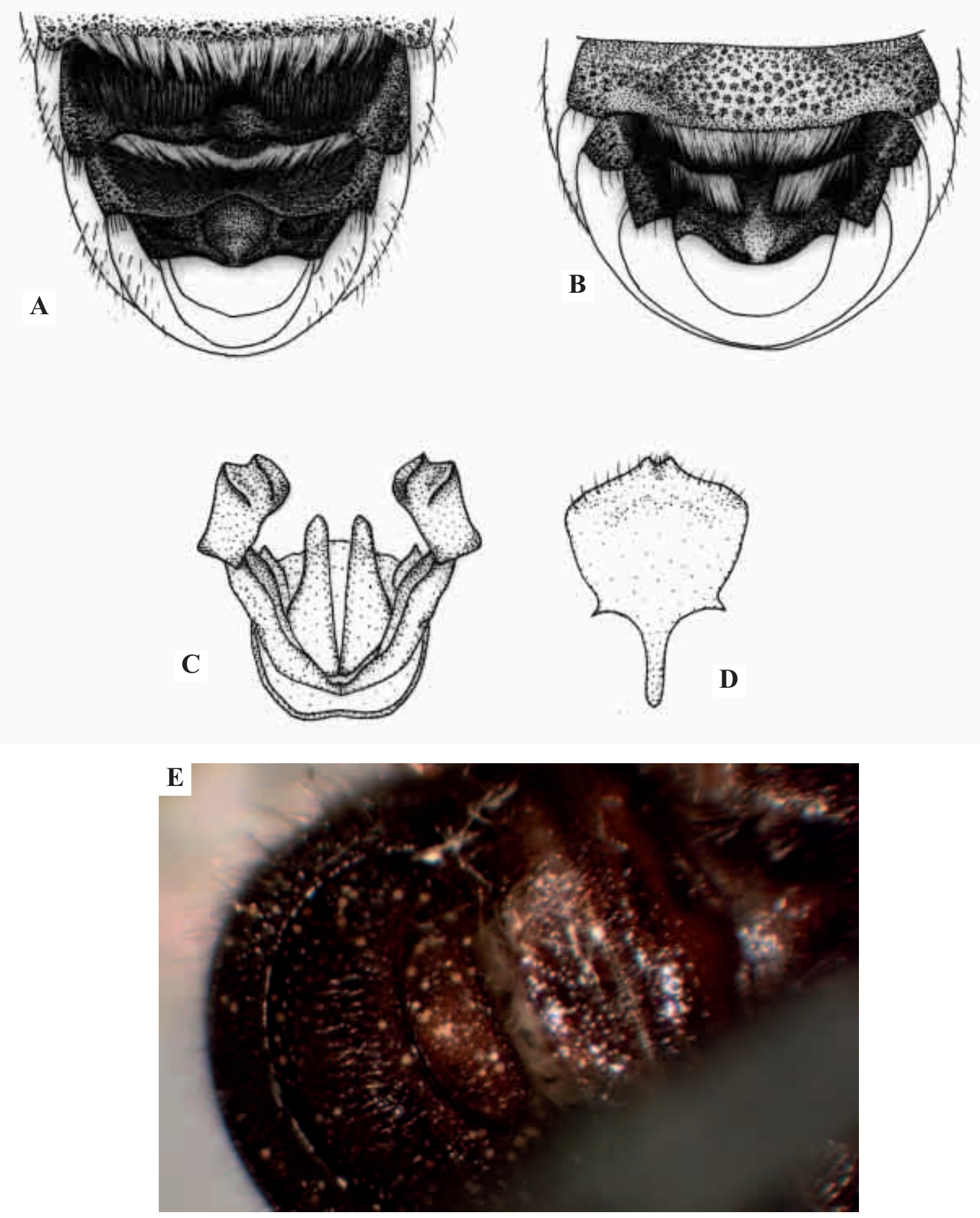

Fig 14.- Vista ventral esquemática del gáster del macho de Stelis simillima (A) y S. breviuscula (B); genitalia (C) y E E $_{8}$ (D) de $S$. simillima; vista ventral del gáster de S. breviuscula (E).

Fig 14.- Stelis simillima (A) and S. breviuscula (B) male gastrum drawings; S. simillima genitalia (C) and $\mathrm{E}_{8}$ (D) drawings; S. breviuscula gastrum in ventral view (E). 

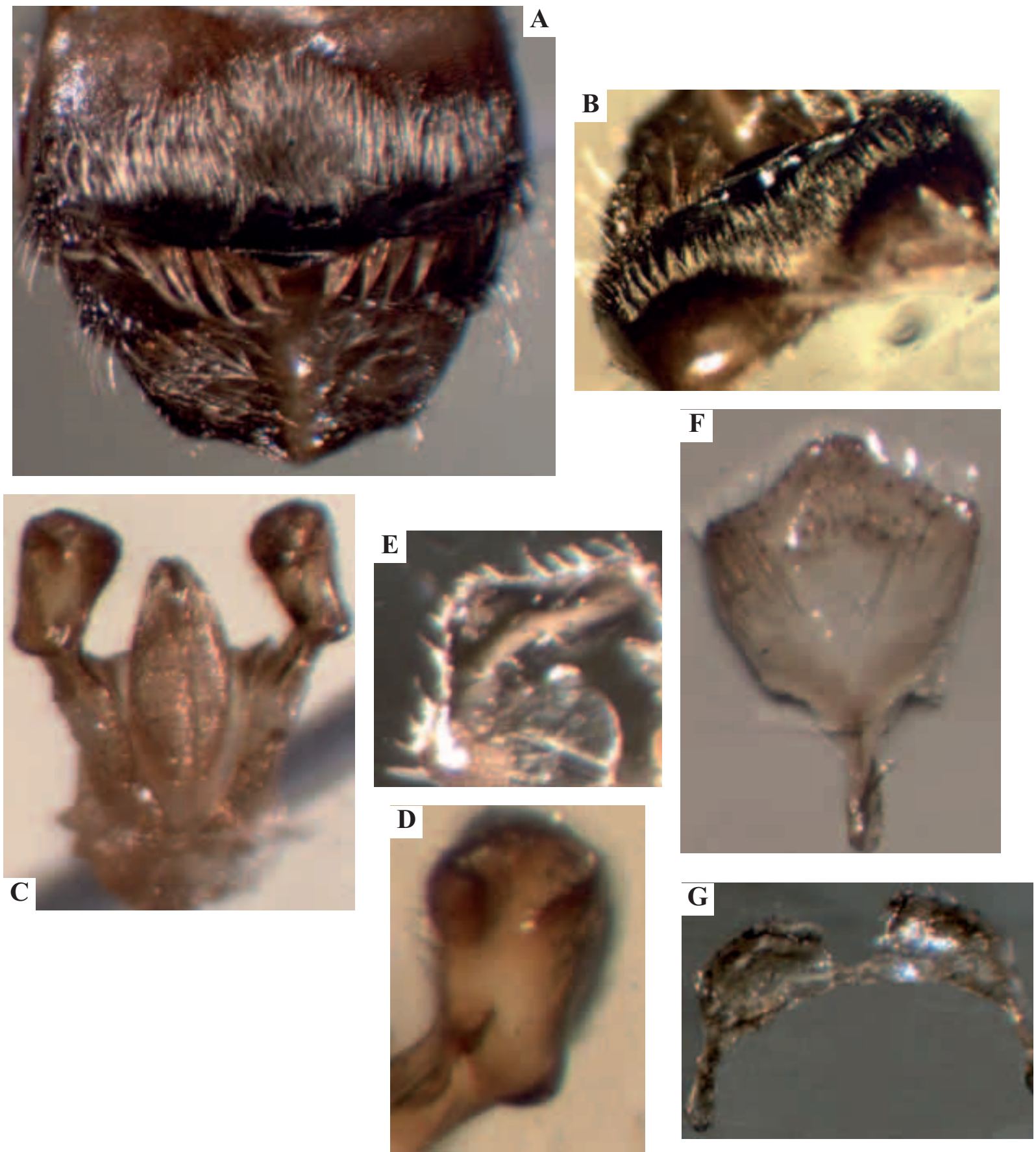

Fig 15.- Macho de Stelis phaeoptera: Esternitos gastrales $\mathrm{E}_{4}, \mathrm{E}_{5}$ y $\mathrm{E}_{6}(\mathrm{~A})$; vista antero-ventral de $\mathrm{E}_{4}(\mathrm{~B})$; genitalia $(\mathrm{C})$ y porción terminal del gonocoxito izquierdo (D); zona distal de $\mathrm{E}_{8}(\mathrm{E})$ y $\mathrm{E}_{8}$ completo $(\mathrm{F}) ; \mathrm{E}_{7}(\mathrm{G})$.

Fig 15.- Stelis phaeoptera male: Gastral sterna $\mathrm{E}_{4}, \mathrm{E}_{5}$ and $\mathrm{E}_{6}(\mathrm{~A}) ; \mathrm{E}_{4}$ in antero-ventral view (B); genitalia $(\mathrm{C})$ and left gonocoxite terminal portion (D); $\mathrm{E}_{8}(\mathrm{~F})$ and its distal apex $(\mathrm{E}) ; \mathrm{E}_{7}(\mathrm{G})$. 

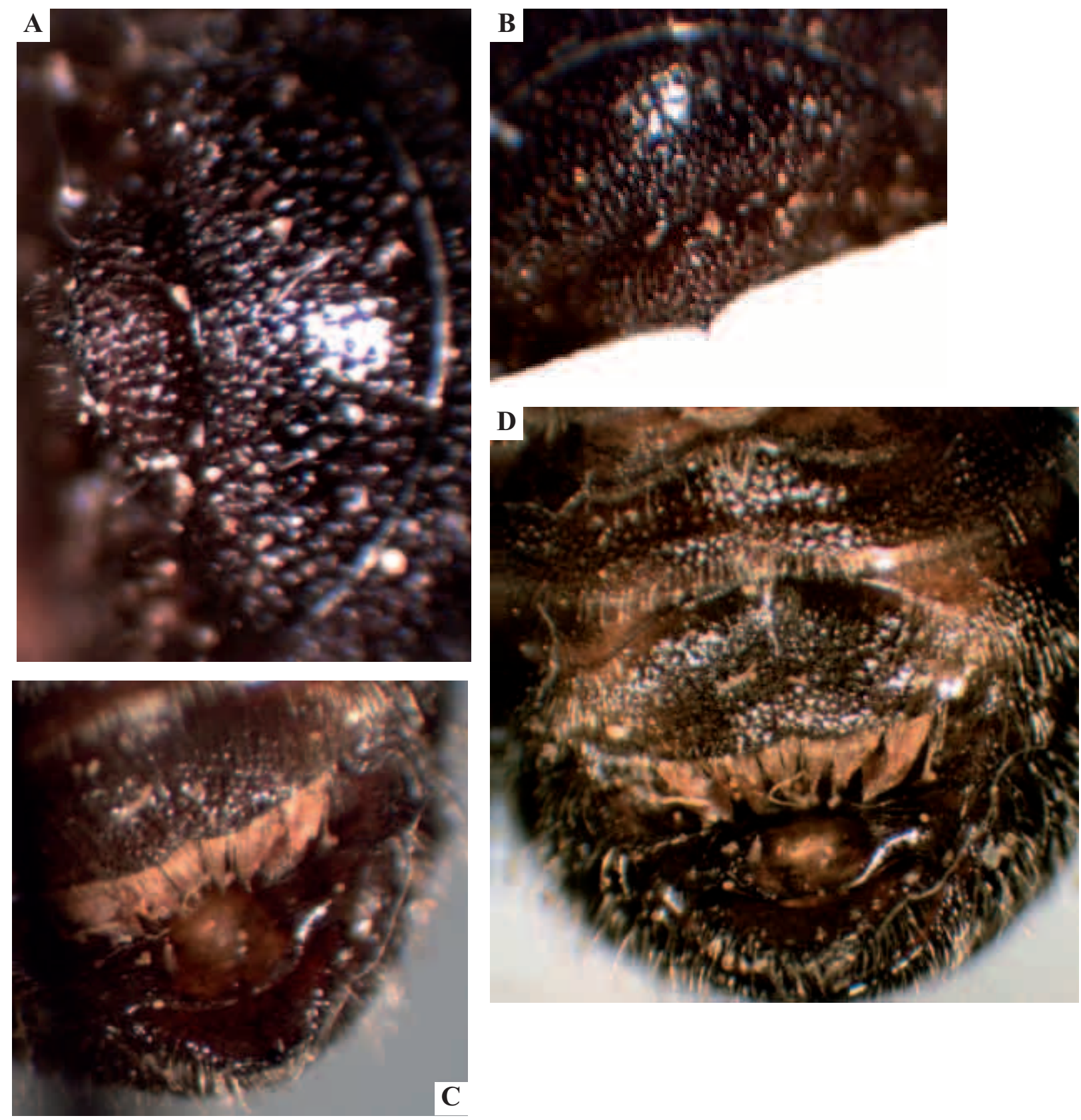

Fig 16.- Macho de Stelis odontopyga: Vista dorsal de $\mathrm{T}_{6} \mathrm{y} \mathrm{T}_{7}(\mathrm{~A})$; extremo de $\mathrm{T}_{7}(\mathrm{~B})$; vista ventral de $\mathrm{T}_{7}, \mathrm{E}_{6}, \mathrm{E}_{5} \mathrm{y}$ borde y pubescencia de $\mathrm{E}_{4}(\mathrm{C})$; gáster en vista ventral $(\mathrm{D})$.

Fig 16. - Stelis odontopyga male: $\mathrm{T}_{6}$ and $\mathrm{T}_{7}$ in dorsal view (A); $\mathrm{T}_{7}$ apex $(\mathrm{B}) ; \mathrm{T}_{7}, \mathrm{E}_{6}, \mathrm{E}_{5}$ and $\mathrm{E}_{4}$ margin and pubescence in ventral view (C); gastrum in ventral view (D). 

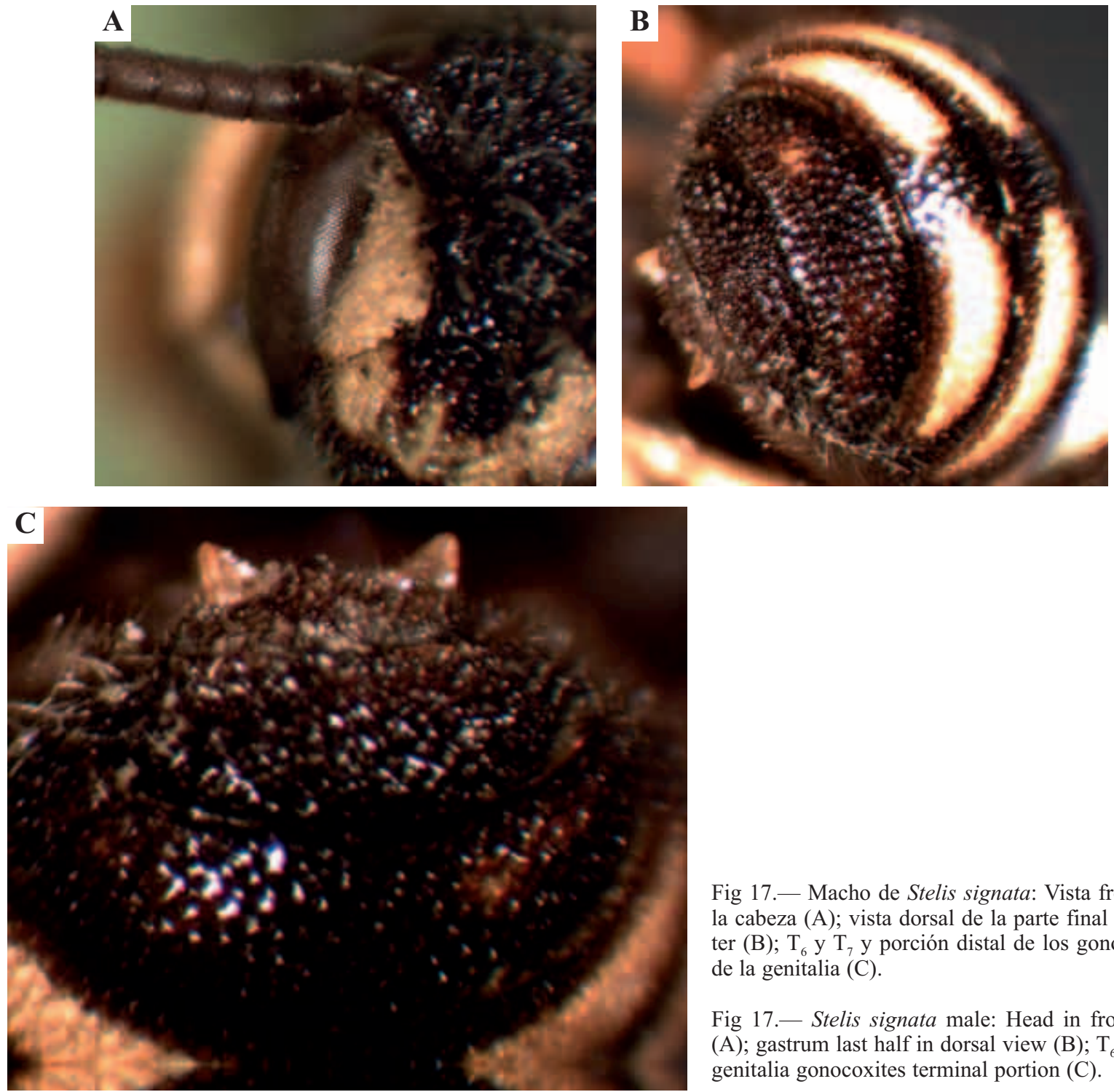

Fig 17.- Macho de Stelis signata: Vista frontal de la cabeza (A); vista dorsal de la parte final del gáster (B); $\mathrm{T}_{6}$ y $\mathrm{T}_{7}$ y porción distal de los gonocoxitos de la genitalia $(\mathrm{C})$.

Fig 17.- Stelis signata male: Head in front view (A); gastrum last half in dorsal view (B); $\mathrm{T}_{6}, \mathrm{~T}_{7}$ and genitalia gonocoxites terminal portion (C).

Nuevos REGISTROS:

- Granada: Sierra Nevada, VII-16-21 (sic), $10^{7}, G^{\mathrm{a}}$ Mercet, Stelis minuta, Col. Ga Mercet, MNCN.

Stelis nasuta (Latreille, 1809)

Especie paleártica occidental, repartida por Europa central y meridional, el norte de África, Oriente Próximo, el Cáucaso y Asia Central, hasta Uzbekistán e Irán (Ornosa et al., 2008). En la Península Ibérica se conocía por medio de citas de Portugal, de Aveiro, Gouveia, Lousa, Miranda do Corvo (Diniz, 1989) y de España, Ávila, Barcelona, Cádiz, Ciudad Real y Madrid (Maidl, 1922; Dusmet, 1921; Ceballos, 1956), y ahora, además por ejemplares antiguos de Barcelona y de Lérida.
Nuevos Registros:

- Barcelona: Centelles, Cataluña 1 \%, Mas de Xaxars, como Stelis sp., MNCN. Lérida: Vernet, 12-VII-1911, P. C., 1 \& ; 30VI-11, 1 우 (en una serie como Stelis sp.), MNCN.

No corresponde a Stelis nasuta:

1 \&, Madrid, Ga Mercet leg. Colección Ga Mercet, MNCN (de la serie de Stelis nasuta), que es Stelis breviuscula.

Stelis ornatula (Klug, 1808)

Especie paleártica occidental, repartida por Europa y el norte de África e Irán, en Asia, donde presenta una subespecie distinta de la nominal (Popov, 1932; Warncke, 1985, 1988 y 1992; Baker, 1999). En la Península Ibérica 

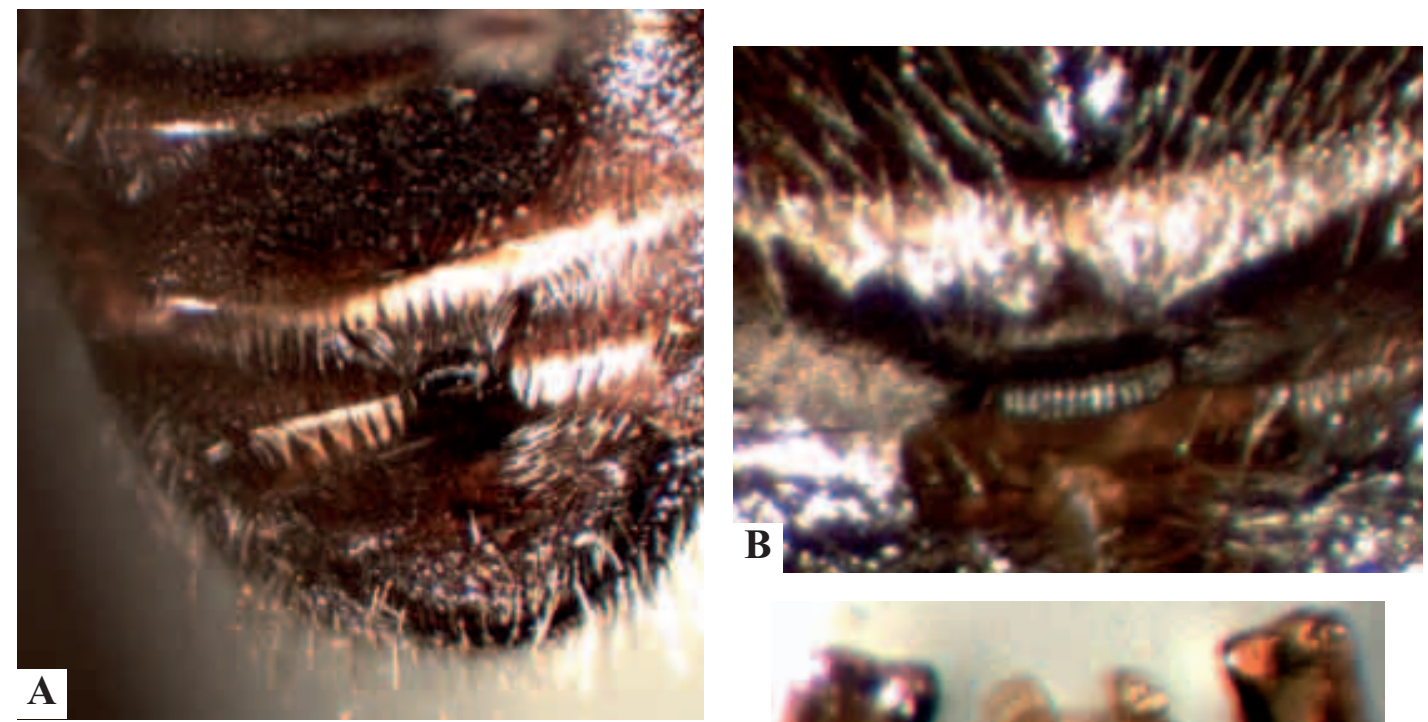

Fig 18. - Macho de Stelis ornatula: Vista ventral del gáster (A); detalle del peine de $\mathrm{E}_{4}(\mathrm{~B})$; genitalia $(\mathrm{C})$.

Fig 18. - Stelis ornatula male: Gastrum in ventral view (A); $\mathrm{E}_{4}$ comb (B); genitalia (C).

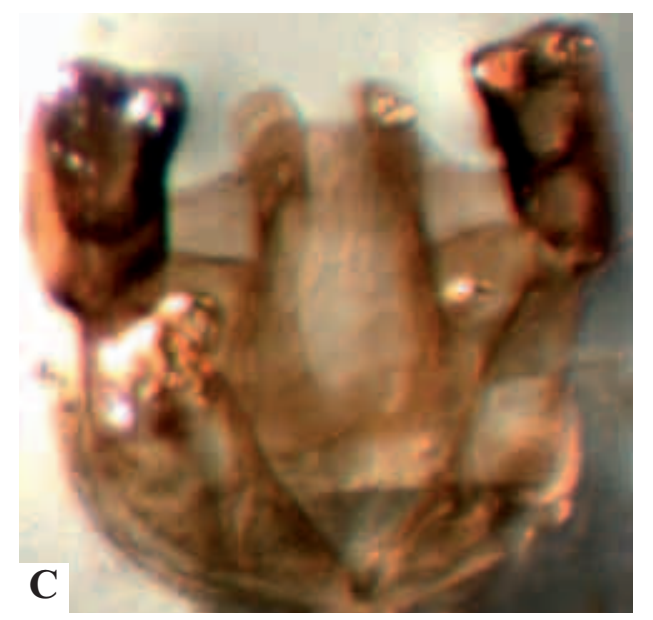

se había localizado hasta ahora en Barcelona y Madrid (Dusmet, 1921; Warncke, 1992). Los registros actuales amplían su distribución ibérica conocida.

\section{NuEVOS REGISTROS:}

- Cáceres: Montehermoso: 6-I-2006, 10 $0^{x}$; 9-I-2006, 2 우 우 ; 20-I-2006 $10^{7}, 1$ q ; F. Torres leg., USAL.

\section{Stelis simillima Morawitz, 1876}

Especie paleártica occidental, distribuida en Europa (incluidos el sur de Rusia y Bulgaria), desde España, a través del Mediterráneo, el norte de África (Marruecos), Asia Menor, el Cáucaso y Kopet-Dagh en Asia Central (Ornosa et al., 2008). En la Península Ibérica había sido citada exclusivamente en la provincia de Huesca (Monzón) (Warncke, 1992). Los registros actuales extienden notablemente su distribución ibérica conocida.

NueVos REgISTROS:

- Almería: Macián, Vélez Blanco, 1200 m., 12-VII-2005, $2 \sigma^{7} \sigma^{\top}$, Ortiz leg., FJOS. Barcelona: Centellas, Cataluña; sin

fecha, $1 \sigma^{7}$; 7-VII-1925, $1 \sigma^{7}$; Mas de Xaxars leg., (en la serie de "Stelis aterrima"), MNCN. Lérida: Gerri de la Sal, 7-VII2009, $2 \sigma^{7} \sigma^{7}$, F. Torres leg., UCM. Soria: Piquera de San Esteban, 30-VII-1990, $1 \sigma^{\pi}$, J. García leg., USAL.

\section{Stelis breviuscula Nylander, 1848}

Especie distribuida por la región paleártica, exceptuado Japón. En Europa llega desde el norte hasta la Península Ibérica y en el norte de África aparece en Argelia (Warncke, 1992; Comba \& Comba, 2001). En la fauna ibérica se había citado en Portugal, de Coimbra, Évora y Soure (Diniz, 1989) y en España, en las provincias de Cádiz, Madrid, Salamanca, Segovia y Tarragona (Dusmet, 1921; Warncke, 1992; Espeso \& Gayubo, 1988; Torres et al., 1989), más Gibraltar (Warncke, 1992). Las citas actuales amplían su distribución ibérica conocida y el rango altitudinal, entre los 2 y los $2000 \mathrm{~m}$.

Nuevos Registros:

- Almería: Ermita Virgen de la Cabeza. Sierra de María, 1400 m., 4-VII-94, 1 o, Ortiz leg., FJOS. Baleares: Mallorca, Can 

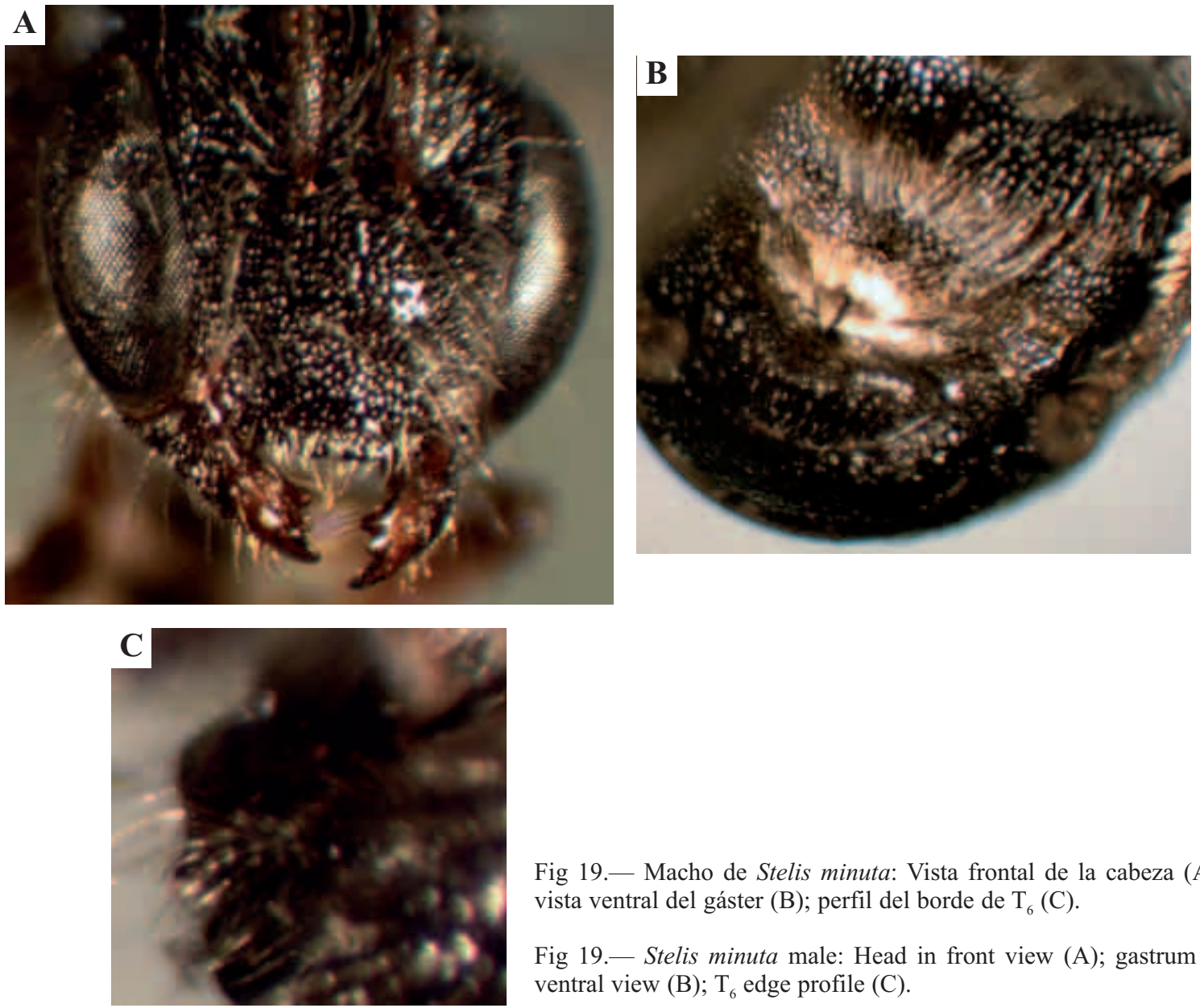

Fig 19.- Macho de Stelis minuta: Vista frontal de la cabeza (A); vista ventral del gáster (B); perfil del borde de $\mathrm{T}_{6}(\mathrm{C})$.

Fig 19.- Stelis minuta male: Head in front view (A); gastrum in ventral view (B); $\mathrm{T}_{6}$ edge profile $(\mathrm{C})$.

Fuster. Manacor, 50 m., 13-VI-1994, $10^{7}$, Ortiz leg., FJOS. Granada: Puerto de la Ragua, Ferreira, Sierra Nevada, 2000 m., 23-VII-2006, 1 \& , Ortiz leg., FJOS. Huelva: Palacio Doñana, 2 m., 18-VI-2005, 1 우, Ortiz leg., FJOS. Salamanca: Saucelle, 2-VIII-1997, 1 ㅇ, S. F-Gayubo leg., USAL.

Stelis punctulatissima (Kirby, 1802)

Se encuentra distribuida en Europa central y meridional, a lo largo del territorio mediterráneo y el Cáucaso (Maidl, 1922; Tkalců, 1970; Warncke, 1992; Baker, 1999; Comba \& Comba, 2001).

En la fauna ibérica (Ornosa et al., 2008) existe la subespecie Stelis punctulatissima hellenica Mavromoustakis, 1960, mediterránea (Península Ibérica, Grecia, Turquía y Marruecos), de Asia Menor (Siria) y el Cáucaso. Se ha citado en Portugal, en el Algarve, Aveiro, Castelo Branco, Castro Marim, Coimbra, Silves, Sines (Maidl, 1922; Ceballos, 1956; Diniz, 1989) y en España, en las provincias de Alicante, Almería, Asturias, Barcelona, Guadalajara,
Huesca, Madrid, Segovia, Salamanca, Valencia y Zaragoza (Dusmet, 1921; Ceballos, 1956; Pérez-Ínigo, 1984; Espeso \& Gayubo, 1988; Torres et al., 1989; Erdlansson, 1991; Warncke, 1992). En nuestra fauna se ha recolectado hasta los $2040 \mathrm{~m}$ de altitud. Los registros actuales confirman y extienden su distribución ibérica conocida.

NuEVOS REGISTROS:

- Alicante: Orihuela, VII-1935, $10^{7}$, Andréu leg.; 21-VI-1922, V. Muedra S.J.; Stelis aterrima (caligrafía de Dusmet), Colección Dusmet, MNCN. Almería: Laujar, España, 18-VII1965, $10^{7}$, J. Suárez, FJOS, Stelis paheoptera, Pasteels det. 1972. Asturias: La Corrada, Avilés, 25-VII-1976, 1 \& ; UCM. Ávila: Navalperal, VII-1904, $10^{7}$, Escalera leg., MNCN; Cuevas del Valle, 21-VII-1987, 1 우, S.F-Gayubo leg.; Mombeltrán, 24-VII-1987, 1 ㅇ, C. Heras, leg.; USAL. Cáceres: Montehermoso, 14-XII-2005, 2 우 우; 22-XII-2005, $10^{\nearrow}, 1$ ㅇ ; F. Torres leg., USAL. Gerona: Camprodón, 14-VIII1898, 1 오 MNCN. Granada: Pradollano (Monachil), 2040 m., 23-VII-2006, $2 \sigma^{7} \sigma^{\star}$, Ortiz leg., FJOS. León: Barrios de S., VI-1994, 1 o ; F. Torres leg., USAL. Madrid: Alameda del Valle, 14-VIII-1978, 107, UCM; Embalse del Vellón, 
Guadalix, 27-VIII-1977, $10^{7}$, Pérez-Íñigo leg., Stelis aterrima Pérez-Íñigo det.; Pontevedra: Bayona, VIII-1922, $1 \sigma^{7}$, Stelis aterrima (caligrafía de Dusmet), Colección Dusmet, MNCN. Salamanca: Salamanca, 4-VII-1986, $1 \sigma^{7}$; 7-VII-1986, 1 ㅇ ; Salto de Aldeadávila, 2-VII-1997, 2 우 ㅇ ; 18-VII-1998, 1 ㅇ ; F. Torres leg.; USAL. Valencia: Segorbe, 1910, $10^{7}$, MNCN. Valladolid: Tordesillas, 15-VII-1997, 1 \& , F. Torres leg.; Viana de Cega, 27-VI-1993, 1 오 , J. A. González leg.; USAL. Sin otros datos: Argental, 1890, $1 \sigma^{7}, \mathrm{MNCN}$.

\section{Stelis phaeoptera (Kirby, 1802)}

Especie paleártica occidental (Ebmer, 2003; Ornosa et al., 2008), con una forma más meridional, Stelis phaeoptera murina Pérez, 1883 (Warncke, 1985 y1992), que se reparte desde Canarias por el área mediterránea. Ésta es la subespecie que existe en la fauna ibérica, citada en Portugal, en Castro Marim, Coimbra, Évora y Serra do Buçaco (Diniz, 1989) y en España, en las provincias de Barcelona, Guadalajara, Jaén, Madrid, Málaga, Murcia, Sevilla, Segovia y Soria (Dusmet, 1921, 1923; PérezÍnigo, 1984) y Gibraltar (Warncke, 1992). Las citas actuales amplían su distribución ibérica conocida.

\section{NUEVOS REGISTROS:}

- Alicante: Orihuela, $1 \sigma^{\pi}$, Andréu leg., Colección Dusmet, Stelis phaeoptera, Dusmet det., MNCN. Cáceres: Guijo de Galisteo, 2004; Cordel, $10^{7}, 4$ 우 ; Cruz Carriles, 2 우 ㅇ Huerto Cristo, $10^{\pi}, 1$ 우 Viña, 1 우, F. Torres leg.; USAL. Cádiz: Puerto de Santamaría, $1 \sigma^{\top}, 1$ 오, Dusmet leg., MNCN. Ciudad Real: Pozuelo, 1 \&, La Fuente leg., Colección Dusmet, Stelis phaeoptera, Dusmet det., MNCN. Gerona: Ribas, 10-VII-1897, $30^{7} \sigma^{7}$, André leg., Stelis phaeoptera, Cabrera det., MNCN. Granada: Granada, 1-VI-1989, $10^{\pi}$, R. Salas leg., v.d. Zanden det.; Granada (UTM: 30SVG4514), 20 III-1977, Ortiz leg., v.d. Zanden det.; FJOS. León: 1 \%, Dusmet leg., Colección Dusmet, Stelis phaeoptera, Dusmet det., MNCN. Madrid: El Escorial, 21-VIII-1978, 1 \& , PérezÍñigo leg., Stelis phaeoptera P.-Íñigo det., UCM. Palencia: Villalcázar de S., 21-VI-1987, 1 \% , A. Rueda leg., USAL. Salamanca: Castillejo, 1994, $10^{7}$; Salto de Aldeadávila, 23-V1998, 1 ㅇ ; 6-VI-1998, 1 ㅇ ; S.F. Gayubo leg.; 5-VII-1998, 1 ㅇ, F. Torres leg.; Salvatierra de T., 1995, $19 \sigma^{7} \sigma^{7}$; sin fecha, $1 \sigma^{\top}$; F. Torres leg.; USAL. Valladolid: Zamadueñas, 1972, 1 ㅇ ; Granja Escuela, E. Asensio, leg., Stelis phaeoptera Asensio det.; $\mathrm{MNCN}^{2}$.

\section{Conclusiones}

Se incluyen en este trabajo las claves ibéricas de hembras y machos del género Stelis, acompañadas

\footnotetext{
Además de los registros correspondientes a las citas de Dusmet (1921), que como en otros casos no se vuelven a pormenorizar ahora, no se han incluido otros tantos de localidades de la provincia de Madrid, de la Colección Dusmet, del MNCN, que se ajustan a varias, sin datos concretos, que de esta provincia mencionaba dicho autor (Dusmet, 1921).
}

de 72 ilustraciones. Tanto las claves como las imágenes incluidas, dibujos y fotografías, son inéditas.

Se aportan, asimismo, nuevas citas y actualización o modificación de registros antiguos, que extienden la distribución ibérica conocida de Stelis breviuscula, Stelis minuta, Stelis nasuta, Stelis ornatula, Stelis phaeoptera, Stelis punctulatissima, Stelis signata y Stelis simillima. En algunas de éstas, las citas actuales son de mayor relevancia al tratarse de la segunda o tercera para esas especies y confirman, además, su presencia en el área considerada. Tal es el caso de Stelis minuta y Stelis simillima, en las que sólo se contaba con una única cita ibérica en Pirineos, de modo que los presentes registros amplían notablemente su distribución conocida en nuestro territorio, o Stelis ornatula, referida aquí exclusivamente de dos localidades peninsulares.

\section{AGRADECIMIENTOS}

A los Doctores Isabel Izquierdo, Amparo Blay, Mercedes París y Miguel Ángel Alonso Zarazaga, por las facilidades y acceso a las colecciones del Museo Nacional de Ciencias Naturales de Madrid y de otras instituciones, a Eduardo Ruiz por las fotografías y a Iñaki Díez Cortaberría y Alexandre Anichtchenko por los dibujos.

\section{Referencias}

BAKER, D. B., 1999. On new Stelidini bees from S.W. Asia and N,W. Africa, with a list of the old-worldtaxa assigned to the genus Stelis Panzer, 1806. Deutsche Entomologische Zeitschrift, 46(2): 231242.

BofILl, J. M., 1905. Catàlech de Insectes de Catalunya. Hymenòpters. Butlletí de la Institució Catalana d' Historia Natural, $\mathrm{n}^{\circ} 7: 41-47, \mathrm{n}^{\circ}$ 8: 48-53.

Ceballos, G., 1956. Catálogo de los himenópteros de España. Trabajos del Instituto Español de Entomología. (C.S.I.C.). Madrid. 554 pp.

Cомва, M. \& CombA, L., 2001. Gli Apoidei (Hymenoptera: Aculeata) alpini: diversità e abbondanza in alcune fasce altitudinali delle Valli del Pellice, Angrogna e Germanasca (Alpi Cozie). Bollettino del Museo regionale di Scienze Naturali di Torino, 18(1): 11-97.

Diniz, M. A., 1989. Catálogo das abelhas portuguesas I. Ciências Biológicas Ecological Systems (Portugal), 9(1/2): 33-39.

Dusmet, J. M., 1921. Los Ápidos de España. V. Géneros Stelis Panz., Dioxys Lep., Ammobates Latr., Phiarus Gerst., Pasites Jur. y Biastes Panz. Memorias de la Real Sociedad española de Historia Natural, Tomo del Cincuentenario: 177-212. 
Dusmet, J. M., 1923. Sobre himenópteros existentes en la colección de la Universidad de Sevilla. Boletín de la Real Sociedad española de Historia Natural, 23: 66.

EBMER, A. W., 2003. Hymenopterologische Notizen aus Österrech -18. Linzer Biologische Beiträge, 35(1): 313-403.

ERLANDSSON, S., 1991. Hymenoptera Aculeata from the European part of the Mediterranean countries. IV. Bollettino del Museo civico di Venezia, [1989], 40: 89-95.

Espeso, M. A. \& Gayubo, S. F., 1988. Apidofauna de la provincia de Segovia. Acta Salmanticensia, 66: 1-81.

FrIESE, H., 1895. Die Bienen Europa's (Apidae europaeae) Teil I. Schmarotzerbienen. Friedländer \& Sohn. Berlin. 218 pp.

MAIDL, F., 1922. Beiträge zur Hymenopterenfauna Dalmatiens, Montenegros und Albaniens. Annalen des Naturhistorischen Museums in Wien, 35: 36-106.

Michener, C. D., 2007. The bees of the world. The Johns Hopkins University Press. Baltimore and London. viii + 913 pp (2nd Edition).

Michener, C. D. \& Griswold, T.L. 1994. The classification of the Old World Anthidiini (Hymenoptera, Megachilide). The University of Kansas Science Bulletin, 55 (9): 299-327.

Noskiewicz, J., 1926. Neue europäische Bienen (Hymenoptera, Apidae). Polskie Pismo Entomologiczne, [1925], 4: 230-237.

Noskiewicz, J., 1961. Beiträge zur Kenntnis der paläartischen Arten der Gattung Stelis Panz. (Hym., Apidae). Polskie Pismo Entomologiczne, 31(12): 113-133.

Ornosa, C., Ortiz-Sánchez, F. J. \& Torres, F., 2008. Catálogo de los Megachilidae del Mediterráneo occidental (Hymenoptera, Apoidea). III. Anthidiini y Dioxyini. Graellsia, 64(1): 61-86.

Pasteels, J. J., 1969. La systématique générique et subgénérique des Anthidiinae (Hymenoptera, Apoidea, Megachilidae) de l'Ancien Monde. Memoires de la Société Royale d'Entomologie de Belgique, 31: 3-148.

PÉrez-ÍñIgO, C., 1984. Los Ápidos de la Sierra de Guadarrama II. Fam. Andrenidae y Megachilidae (Hym., Apoidea). Graellsia, [1983], 39: 103-126.

Popov, V. B., 1932. On the palearctic forms of the tribe Stelidini Roberts (Hymenoptera, Megachilidae). Trudy Zoologischeskogo Instituta Akademia Nauk SSSR, Leningrado, 1: 375-414.

Popov, V. B., 1935. Beitrag zur Kenntnis der paläarktischen Stelis-Arten (Hymenoptera, Apoidea). Folia Zoologica et Hydrobiologica, 7: 216-221.
Popov, V. B., 1938. Notiz über die Gattung Chelynia Prov. und einige Untergattungsgruppierungen der Gattung Stelis Panz. Hymenoptera (Apoidea). Konowia, 17: 36-41.

Radoszkowski, O., 1862. Sur quelques Hyménoptères nouveaux ou peu connus. Bulletin de la Société Impériale des Naturalistes de Moscou, 35: 289-298, planche I.

TKALCŮ, B. 1970. Stelis moravica sp. n. aus der Tschechoslowakei, samt Bemergungen zu den verwandten Arten (Megachilidae, Apoidea, Hym.). Acta Musei Moraviae, 55: 195-208.

Torres, F., Gayubo, S. F. \& Asensio, E., 1989. Efecto de la presión urbana sobre abejas y avispas (Hymenoptera, Aculeata) en Salamanca. V. Superfamilia Apoidea. Comunicaciones del INIA. Serie Recursos Naturales, 52: 1-49.

WARNCKE, K., 1985. Beitrag zur Bienenfauna des Iran. 21. Die Gattung Stelis Pz. Bollettino del Museo civico di storia naturale di Venezia, [1983], 34: 237-240.

WARNCKE, K., 1988. Isolierte Bienenvorkommen auf dem Olymp in Griechenland (Hymenoptera, Apidae). Linzer biologische Beiträge, 20(1): 83-117.

WARnCKE, K., 1992. Die westpaläarktichen Arten der Bienengattung Stelis Panzer, 1806. Entomofauna, 13(22): 341-376.
Recibido; 7-VII-2009

Aceptado, 28-X-2009

Publicado, 31-XII-2009 